\title{
Effects of fibroblast growth factor 21 on the heart
}

\author{
Pongpan Tanajak $^{1,2}$, Siriporn C Chattipakorn ${ }^{1,3,4}$ and Nipon Chattipakorn ${ }^{1,2,3}$ \\ ${ }^{1}$ Cardiac Electrophysiology Research and Training Center, Faculty of Medicine, ${ }^{2}$ Cardiac Electrophysiology Unit, \\ Department of Physiology, Faculty of Medicine, ${ }^{3}$ Center of Excellence in Cardiac Electrophysiology Research, and \\ ${ }^{4}$ Department of Oral Biology and Diagnostic Sciences, Faculty of Dentistry, Chiang Mai University, Chiang Mai \\ 50200, Thailand
}

Correspondence should be addressed to $\mathrm{N}$ Chattipakorn Email ncchattip@gmail.com

\begin{abstract}
Fibroblast growth factor 21 (FGF21) is a novel polypeptide ligand that has been shown to be involved in several physiological and pathological processes including regulation of glucose and lipids as well as reduction of arteriosclerotic plaque formation in the great vessels. It has also been shown to exert cardioprotective effects in myocardial infarction, cardiac ischemiareperfusion injury, cardiac hypertrophy and diabetic cardiomyopathy. Moreover, FGF21 protects the myocardium and great arteries by attenuating remodeling, inflammation, oxidative stress and also promoting the energy supply to the heart through fatty acid $\beta$-oxidation. This growing evidence emphasizes the important roles of FGF21 in cardioprotection. This review comprehensively summarizes and discusses the consistent and inconsistent findings regarding the beneficial effects of FGF21 on the heart available from both basic research and clinical reports. The details of the signaling, biological and pharmacological effects of FGF21 with regard to its protection of the heart are also presented and discussed in this review.
\end{abstract}

\section{Key Words}

- fibroblast growth factor 21

- myocardial injury

- cardiac metabolism

- oxidative stress

\section{Introduction}

Fibroblast growth factors (FGFs) are polypeptide chains that have paracrine, autocrine or endocrine functions. The paracrine FGFs are further divided into five subfamilies, whereas the autocrine and endocrine FGFs are composed of one subfamily each (Itoh \& Ornitz 2011, Itoh \& Ohta 2013) (Fig. 1). FGFs act through cell surface FGF receptors (FGFRs), which are regulated by four types of genes including FGFR1, FGFR2, FGFR3 and FGFR4 (Mohammadi et al. 2005, Beenken \& Mohammadi 2009, Goetz \& Mohammadi 2013). Although FGFRs are essential for FGF action on the target cells, they cannot activate intracellular signaling without co-receptors (Kharitonenkov 2008). Previous studies show that heparan sulphate proteoglycans are essential co-receptors for paracrine and autocrine FGFs (Beenken \& Mohammadi 2009,
Goetz \& Mohammadi 2013), whereas Klothos are essential co-receptors for endocrine FGFs to mediate their attachment to and activation of target FGFRs (Suzuki et al. 2008, Beenken \& Mohammadi 2009, Goetz $\&$ Mohammadi 2013).

FGF21 is an endocrine FGF that consists of 209 amino acids. The FGF21 ligand is produced from several organs such as the liver and adipose tissue (Ito et al. 2000), skeletal muscle (Joki et al. 2015), and the heart (Nishimura et al. 2000, Kharitonenkov 2009, Planavila et al. 2013, Patel et al. 2014). To activate FGF21 signaling, FGF21 binds to FGFR1c with its C-terminus, and also with $\beta$-Klotho as its co-receptor with its N-terminus, to form the FGFR/ $\beta$-Klotho complex (Kharitonenkov 2008, Suzuki et al. 2008, Yie et al. 2009, Ding et al. 2012, Hale et al. 2012).

Published by Bioscientifica Ltd 


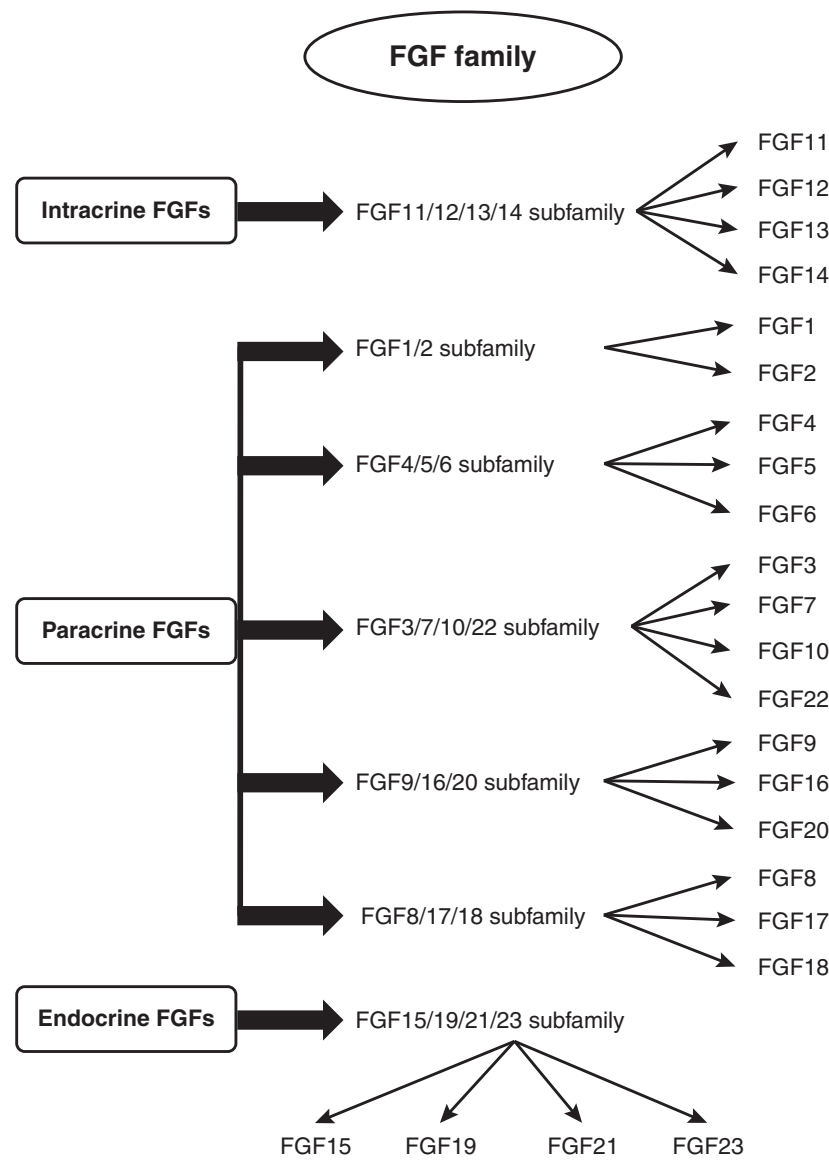

Figure 1

Fibroblast growth factors. FGFs have 22 members which can be divided into three classes and subdivided into seven subfamilies. Intracrine FGFs (11/12/13/14 subfamily); Paracrine FGFs (1/2 subfamily, 4/5/6 subfamily, 3/7/10/22 subfamily, 9/16/20 subfamily, and 8/17/18 subfamily); Endocrine FGFs (15/19/21/23 subfamily). Data from Itoh \& Ohta (2013) and Itoh \& Ornitz (2011).

The FGFR/ $\beta$-Klotho complex then stimulates the autophosphorylation of the fibroblast receptor substrate 2 alpha (FRS2 $\alpha$ ), which is the first step in the downstream signaling of FGF21 (Kharitonenkov 2008, Suzuki et al. 2008). However, FGF21 is believed to have no action in physiological conditions since FGF21 knockout (FGF21$\mathrm{KO})$ mice were found to have normal development (Badman et al. 2009), and did not develop any pathological conditions such as insulin resistance (Hotta et al. 2009, Potthoff et al. 2009). Nevertheless, future studies are needed to evaluate this hypothesis.

FGF21 has been shown to play an important role in pathological processes, such as the regulation of plasma glucose level (Nishimura et al. 2000) and fatty acid $\beta$ oxidation (FAO) which is the primary energy source for the myocardium (Vega et al. 2000, Planavila et al. 2013).
Under stress conditions, FGF21 has been shown to reduce the apoptosis of Islet $\beta$ cells (Wente et al. 2006), hepatocytes (Yu et al. 2015), vascular cells (Wu et al. 2014), cardiac endothelial cells (Lu et al. 2010) and cardiomyocytes (Cong et al. 2013, Liu et al. 2013). Interestingly, FGF21 also protects the heart from apoptosis and remodeling through the activation of adiponectin release to activate the adiponectin signaling pathways (Joki et al. 2015). Currently, the biological and pharmacological mechanism of FGF21 in cardioprotection is still to be elucidated. This review will focus on the effects of FGF21 and its roles in the heart. The consistent and inconsistent findings regarding the beneficial effects of FGF21 in the heart available from both basic research and clinical reports are comprehensively summarized and discussed. The details of the signaling, biological and pharmacological effects of FGF21 with regards to its protection of the heart are also presented and discussed in this review.

\section{Effects of FGF21 on the heart}

FGF21 is synthesized and expressed in the heart by cardiomyocytes (Planavila et al. 2013) and cardiac microvascular endothelial cells (CMECs) (Lu et al. 2010). A previous study demonstrated that cardiomyocytes secrete FGF21 into the media culture in basal conditions at a rate of $\sim 0.05 \mathrm{ng} / \mathrm{ml}$ per $24 \mathrm{~h}$ (Planavila et al. 2013). In the heart, FGF21 ligands act via the FGFR1c (Suzuki et al. 2008, Liu et al. 2013, Planavila et al. 2013, Wu et al. 2014), and FGFR3 (Suzuki et al. 2008, Liu et al. 2013), utilizing $\beta$-Klotho as a co-receptor (Suzuki et al. 2008, Liu et al. 2013, Planavila et al. 2013). Endogenous and exogenous FGF21 plays an anti-apoptotic role in both in vitro and in vivo models, partially through the adiponectin signaling cascade (Joki et al. 2015). Recent studies found that FGF21 protects against isoproterenol (ISO) induced cardiac hypertrophy by activating anti-oxidative pathways (Planavila et al. 2013, 2014) and promoting FAO (Planavila et al. 2013). FGF21 also protects the heart from ischemic reperfusion (I/R) injury and myocardial infarction (MI) by activating several survival pathways (Cong et al. 2013, Liu et al. 2013, Patel et al. 2014). Moreover, FGF21 deficiency accelerated the development of diabetic cardiomyopathy (DCM) (Yan et al. 2015). In contrast, FGF21 administration also prevents lipotoxicity and diabetes induced cardiac apoptosis in DCM (Zhang et al. 2015a).

Interestingly, Liu and colleague demonstrated that the endogenous FGF21 which acted as endocrine protection in the ischemic myocardium was not from the heart but from the liver and adipose tissue (Liu et al. 2013),

Published by Bioscientifica Ltd. 
indicating that the major endogenous FGF21 proteins which preserve cardiac function are from the liver and adipose tissues. Although FGF21 from cardiomyocytes is not a major source, previous studies demonstrated that the autocrine action of FGF21 from cardiomyocytes is essential and could protect the heart from pathological conditions such as cardiomyocyte hypertrophy and $\mathrm{I} / \mathrm{R}$ injury (Planavila et al. 2013, 2014).

\section{Effects of FGF21 on myocyte apoptosis and myocardial infarction}

Myocardial ischemia and I/R injury induce cell apoptosis and MI, leading to an impairment in cardiac function. Growing evidence from both in vitro and in vivo studies demonstrate that exogenous FGF21 protected the cardiomyocytes from apoptosis and MI, and improved cardiac function through activating the PI3K-Akt1-BAD pathway in FGF21-KO mice (Liu et al. 2013), and Akt-GSK3 $\beta$-caspase 3 dependent pathways in H9c2 cell lines (Cong et al. 2013), resulting in the suppression of caspase 3 induced apoptosis. It was proposed that the activation of these pathways would lead to a decrease in the myocardial infarct area and increase cardiac function (Liu et al. 2013, Patel et al. 2014).

Evidence regarding the effects of FGF21 on inhibiting cardiovascular cell apoptosis in in vitro models is summarized in Table 1. FGF21 protects H9c2 cells from I/R injury in a dose dependent manner by promoting the energy supply, and reducing inflammation and apoptosis through the Akt-GSK3 $\beta$ pathway (Cong et al. 2013). On other hand, a previous study found peroxisome proliferator activated receptor alpha (PPAR $\alpha$ ) activation led to the synthesis and release of FGF21. FGF21 was released into the culture media, and protected the CMECs from lipotoxicity induced by Ox-LDL by decreasing DNA fragmentation in an autocrine manner (Lu et al. 2010). In an ex vivo model of global cardiac ischemia, it has been shown that recombinant rat FGF21 infusion 10 min prior to ischemia can protect the heart from $\mathrm{I} / \mathrm{R}$ injury by decreasing MI and increasing the cardiac function through activation of the MAPK-PI3k-Akt signaling pathway (Patel et al. 2014). Moreover, FGF21 prevented oxidative stress (Cong et al. 2013, Planavila et al. 2014), and also increased the energy supply for cardiomyocytes in H9c2 cell lines under I/R injury conditions (Cong et al. 2013).

In addition to in vitro reports, evidence regarding the effects of FGF21 on cell apoptosis and myocardial infarction in in vivo models is summarized in Table 2 . In FGF21-KO mice, FGF21 given intravenously at $50 \mathrm{ng} / \mathrm{g}$ per day for 3 days with the first dose being given immediately after $\mathrm{I} / \mathrm{R}$ injury ( $I=30 \mathrm{~min}, R=1-30$ days), had been shown to protect the heart from apoptosis, MI, and also increase cardiac function through activation of the FGFR1/ß-Klotho-PI3K-Akt1-BAD signaling cascade (Liu et al. 2013). The acute MI in C57BL/6 mice showed that an i.v. injection of Recombinant mouse FGF21 $10 \mathrm{ng} / \mathrm{g}$ in a single dose immediately post MI, which was caused by a left anterior descending coronary artery ligation, decreased the infarction area. It was also shown that these protective effects could be reversed by SiRNA-FGF21 intravenously injected 1 day prior to MI (Liu et al. 2012). Moreover, in chronic MI (2 weeks) C57BL6 and adiponectin-KO mice models it was demonstrated that FGF21 protein derived from skeletal muscles protected the heart from apoptosis through adiponectin signaling (Joki et al. 2015). In addition, FGF21 $100 \mu \mathrm{g} / \mathrm{kg}$ per day s.c. injections for 4 weeks could protect the abdominal aorta from arteriosclerotic lesions through lipid regulation and ER stress induced vascular cell apoptosis in the ApoE-KO model (Wu et al. 2014).

All of these findings indicate that exogenous and endogenous FGF21 play an important role in protecting the heart from apoptosis via several pathways including PI3K-Akt1-BAD and Akt-GSK3ß-caspase 3 dependent mechanisms, leading to decreased infarction and increased left ventricular function under I/R injury, lipotoxic and MI conditions.

\section{Molecular basis of anti-apoptosis signaling cascades of FGF21}

The anti-apoptotic signaling cascade of FGF21 from in in vitro and in in vivo models previously mentioned are summarized in Fig. 2. After FGF21 binding to FGFR1 and $\beta$-klotho via its $\mathrm{N}$-terminus and C-terminus, respectively, the FGF21 ligand induces dimerization of receptors, and the autophosphorylation of tyrosine kinase recruits and phosphorylates FRS2 $\alpha$. In later steps, the anti-apoptotic signaling pathways in cardiomyocytes could be activated through 4 major survival pathways, including Erk1/2, ROR $\alpha$, PI3k-Akt and AMPK signaling pathways. Currently, the downstream signaling proteins involved in these processes are still unclear (Patel et al. 2014).

Previous studies demonstrated that the downstream signaling cascades of FGF21 begin with the autophosphorylation of the receptor after the binding of FGF21. This leads to the phosphorylation of FRS $2 \alpha$, and subsequent activation of PI3K (Liu et al. 2013, Patel et al. 2014, Yu et al. 2015) following its phosphorylation at Serin 458

Published by Bioscientifica Ltd. 

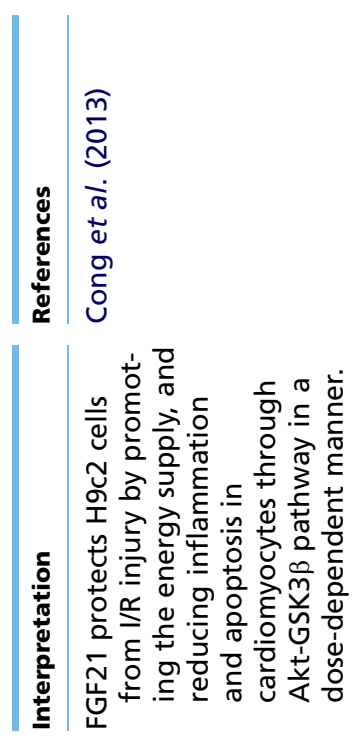
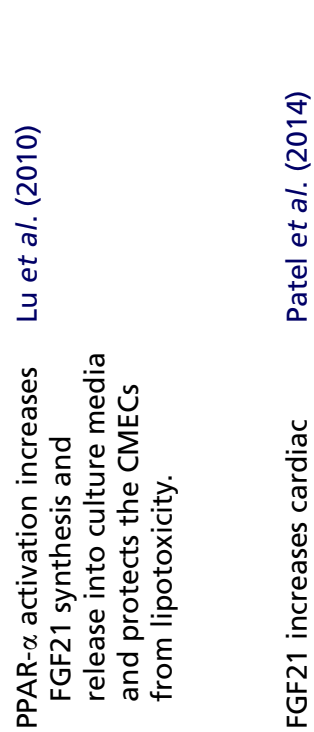

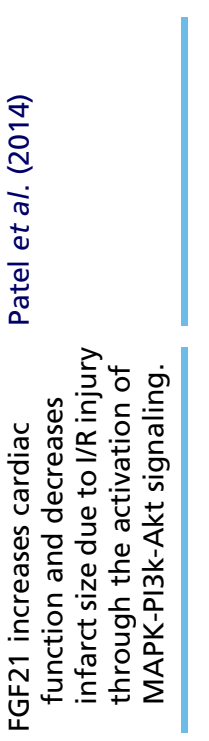

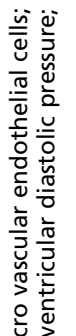

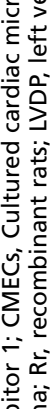

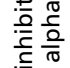
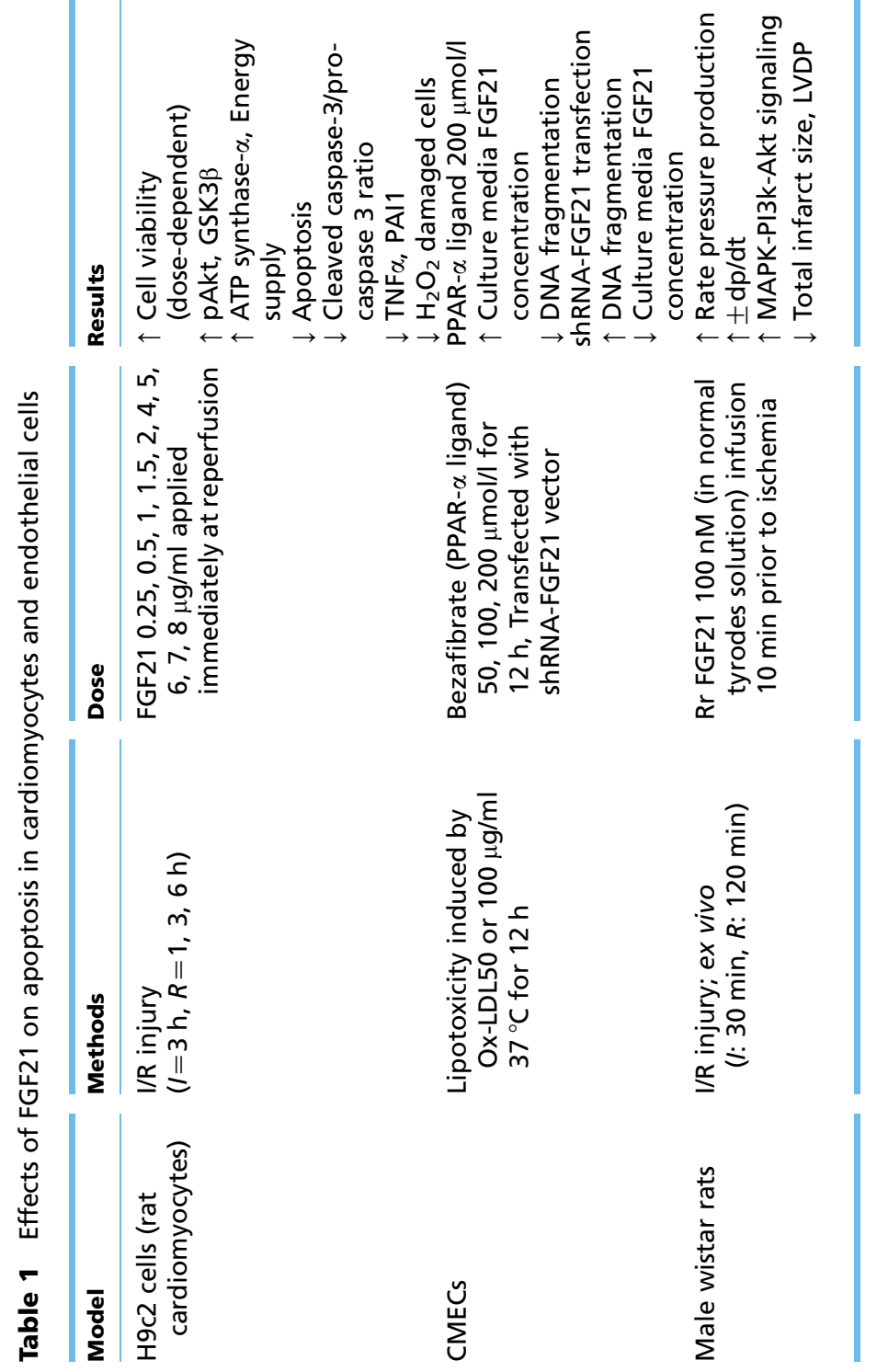

$\sum_{u}^{\breve{u}}$
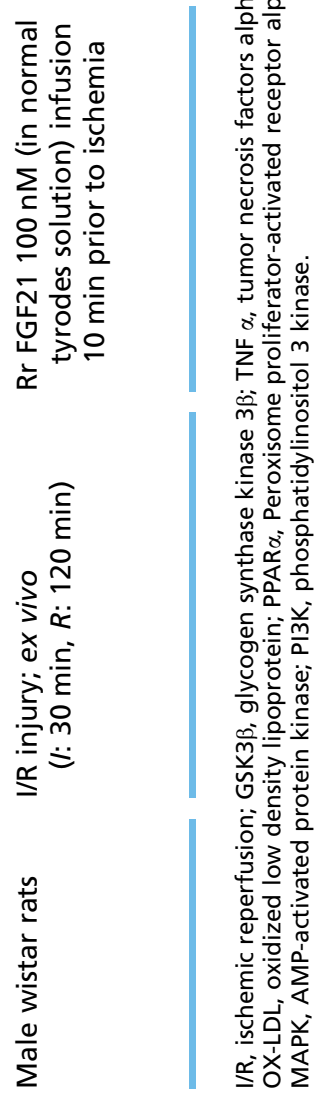


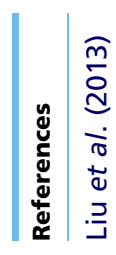

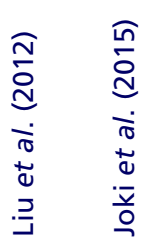

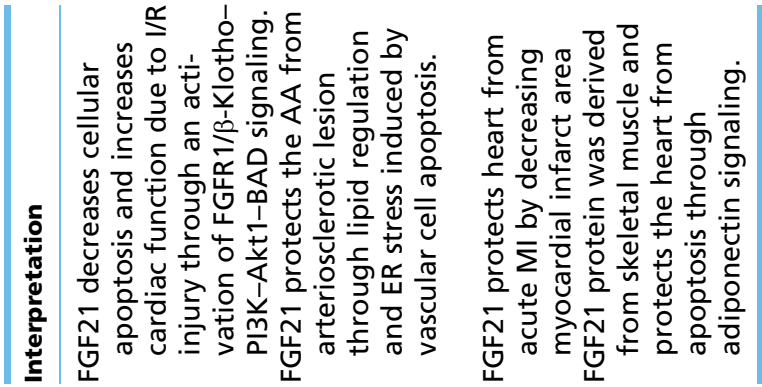

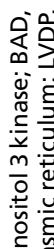
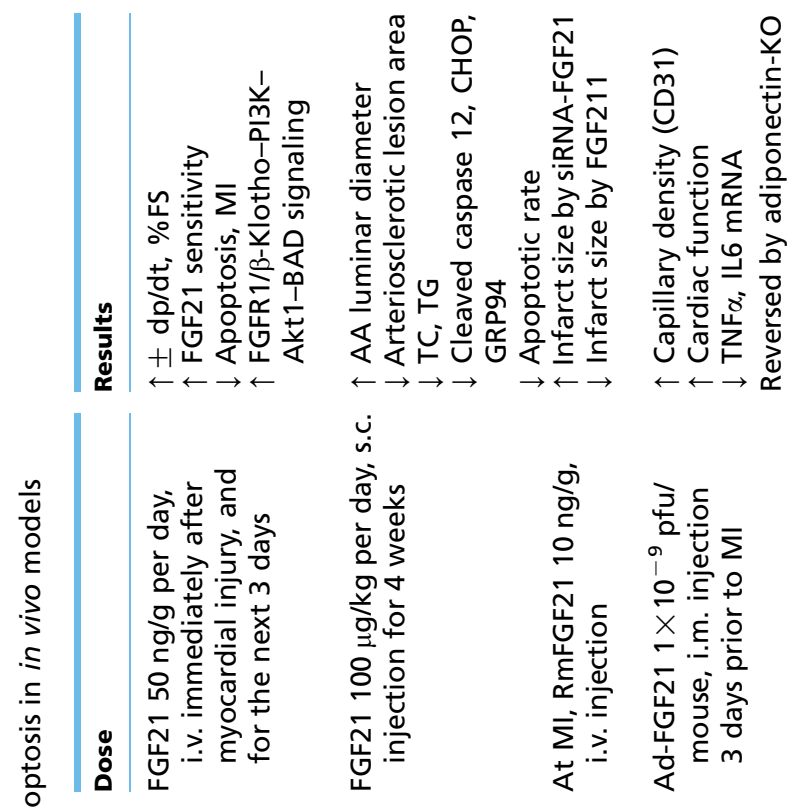

:ั

(a)

$\mid \frac{1}{0}$

$\stackrel{m}{i}$

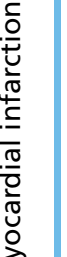

है

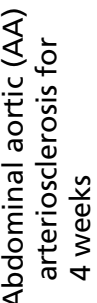

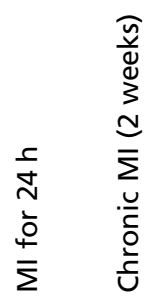

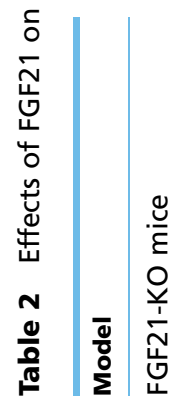
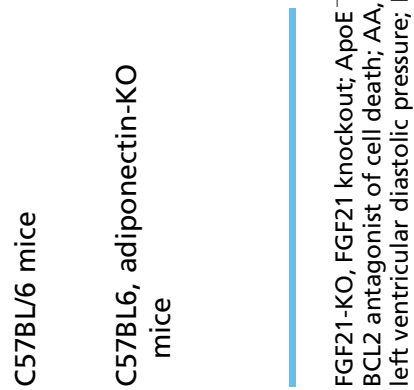


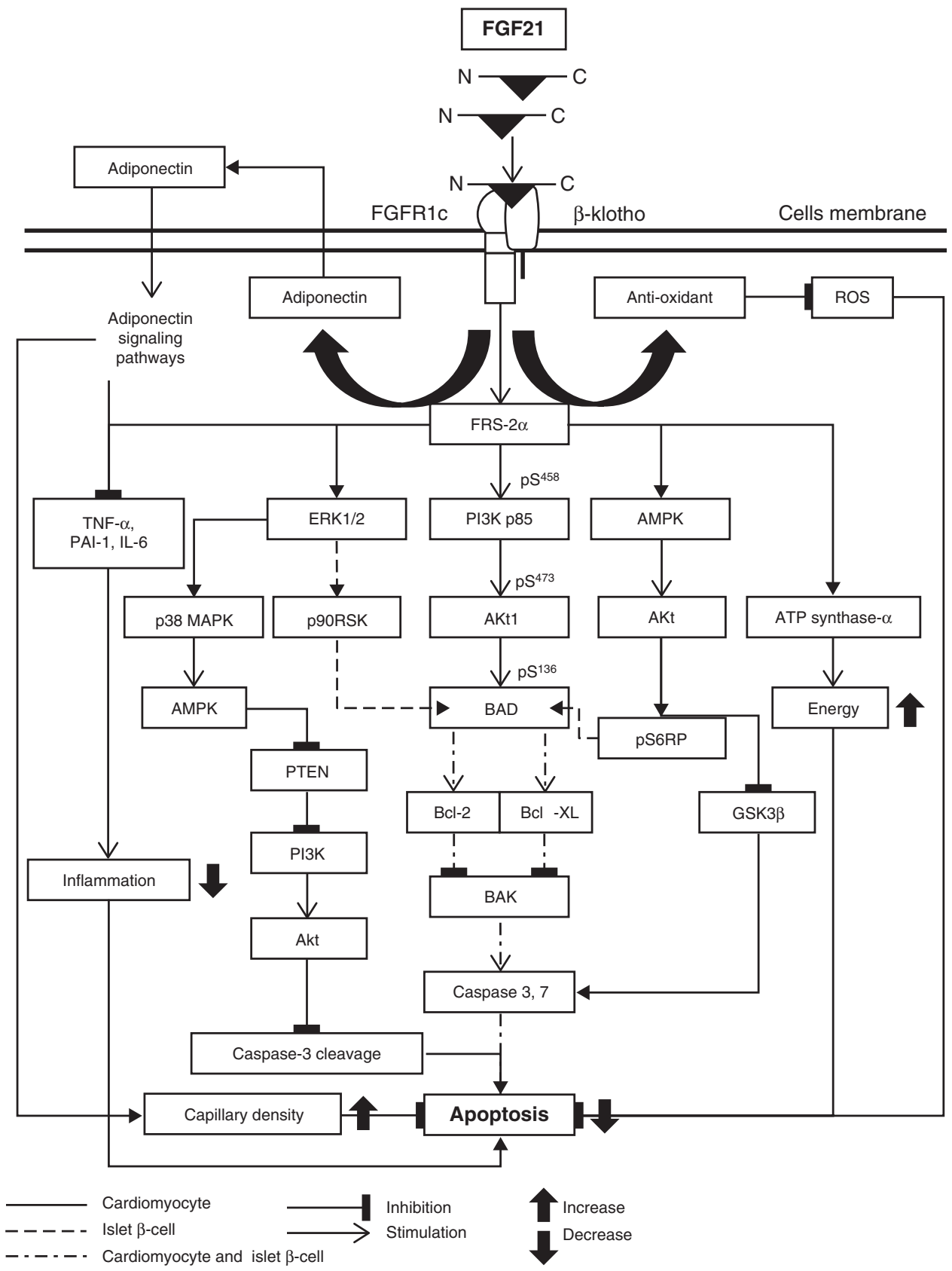

Figure 2

FGF21 signaling cascade in anti-apoptotic effects. FGF21 exerts antiapoptotic effects in cardiomyocytes through decreased inflammation improved FAO metabolism, increased capillary density and anti-oxidative stress. FGF21, Fibroblast growth factors 21; FGFR1c, Fibroblast growth factors receptors $1 \mathrm{c} ; \mathrm{N}, \mathrm{N}$-terminus residue of FGF21 or Amino acid terminal; C, C-terminus residue of FGF21 or Carboxylic terminal; FRS $2 \alpha$, Fibroblast growth factors substrate $2 \alpha$; ROR, Retinoic acid receptor-related

$\left(\mathrm{pS}^{458}\right)$. This leads to the recruitment and phosphorylation of a secondary messenger Akt1 by phosphorylation at Serine $473\left(\mathrm{pS}^{473}\right)$. Akt1 in turn activates the BCL2 antagonist of cell death (BAD) by inducing the

\begin{tabular}{|lr} 
http://joe.endocrinology-journals.org & ○ 2015 Society for Endocrinology \\
DOI: $10.1530 /$ JOE-15-0289 & Printed in Great Britain
\end{tabular}

receptor; Erk1/2, Extracellular signal-regulated kinases 1/2; p90RSK, p90 ribosomal s6 kinase; pS6RP, pS6 ribosomal protein; AMPK, AMP dependent protein kinase; PI3K P85, Phosphatidylinositide-3 kinase P85; GSK3 $\beta$,

Glycogen synthase kinase-3b; BAD, BCL2 antagonist of cell death; $B C L 2, B$ cell lymphoma 2; $B C L-X L, B$ cell lymphoma-extra-large; $B A X, B C l 2$ associated $X$ protein; $\mathrm{BAK}, \mathrm{BCl} 2$ homologous antagonist killer; $\mathrm{TNF} \alpha$, tumor necrosis factors $\alpha$; IL6, interleukin 6; PAI1, plasminogen activator inhibitor 1.

phosphorylation of BAD at Serine136 $\left(\mathrm{pS}^{136}\right)$. his causes BCL2 and BCL-XL to inhibit BAX and BAK induced caspase3/7 activity, which leads to decreased apoptosis in cardiomyocytes (Liu et al. 2013). In addition, FGF21 has

Published by Bioscientifica Ltd 
been shown to inhibit apoptosis through another alternative pathway by activating Akt, thereby inhibiting GSK3 $\beta$, thus leading to decreased caspase 3 activity (Akt-GSK3 $\beta$ caspase 3 dependent pathways) (Cong et al. 2013) (Fig. 2). Moreover, FGF21 can protect the heart from apoptosis by activation of the Erk1/2-p38 MAPK-AMPK survival pathway (Zhang et al. 2015a). Evidence from these reports confirmed that FGF21 plays a critical role in myocardial protection and anti-apoptosis following myocardial injury (Patel et al. 2014, Joki et al. 2015, Zhang et al. 2015a).

Due to the potential cardioprotective benefits of FGF21, it is possible that FGF21 could be used to prevent and/or treat the myocardial apoptosis due to I/R injury or MI. However, evidence related to the roles of the time course of FGF21 administration and its beneficial effects to the pathological heart are still lacking.

\section{Effects of FGF21 on cardiac hypertrophy and adverse cardiac remodeling}

Myocardial ischemia resulting from coronary artery disease (CAD) is the primary cause of MI which could impair cardiac function by reducing the ejection fraction (EF), leading to insufficient oxygen supply to body tissues (Gheorghiade \& Bonow 1998, Joki et al. 2015). This contributes to progression to cardiac hypertrophy and heart failure due to the compensatory mechanisms of the circulatory system to maintain the EF and carry oxygen to peripheral metabolic tissues, known as cardiac remodeling. This long-term maladaptive remodeling can cause increased ventricular hypertrophy, ventricular dilatation, interstitial growth and cardiac fibrosis (Neely et al. 1972).

Evidence regarding the effects of FGF21 on protection against adverse cardiac remodeling and hypertrophy in in vitro and in vivo models is summarized in Table 3. In a single in vitro study, pre-treatment with FGF21 protects neonatal cardiomyocytes (NCMs) from phenylephrine induced hypertrophy by promoting FAO gene expression, attenuating inflammation and oxidative stress through the activation of Sirt1 and Erk1/2-CREB signaling pathways (Planavila et al. 2013). This study also demonstrated that the Sirt1-PPAR $\alpha$ pathway plays an important role in the control of FGF21 expression in the heart.

Evidence from in vivo studies demonstrate that continuous administration of ISO via s.c. infusion for 7 days in FGF21-KO mice induced cardiomyopathy and led to MI, impaired cardiac metabolism and loss of cardiac function in the rat heart (Heather et al. 2009, Planavila et al. 2013). Interestingly, the endocrine function of FGF21 derived from skeletal muscles attenuated cardiac hypertrophy, and reversed the adverse cardiac remodeling process, leading to improved left ventricular function in this chronic MI mice model (Joki et al. 2015). In FGF21-KO mice, it has been shown that FGF21 attenuated cardiac hypertrophy by decreasing hypertrophic markers including atrial natriuretic factor (ANF) and $\alpha$ skeletal actin (aSKA) (Planavila et al. 2013). Moreover, FGF21 decreased the heart weight/body weight ratio and cardiomyocytes area, and also improved cardiac function (Planavila et al. 2013, 2014).

In summary, the protective effects of FGF21 against cardiac hypertrophic damage have been evidenced. Conversely, FGF21 deficiency was found to enhance the induction of cardiac hypertrophy by promoting proinflammatory pathways, oxidative stress, cardiac fibrosis and impairing cardiac metabolism (Planavila et al. 2013, 2014). Results confirmed that cardiac FGF21 has an impact on activation of the autocrine loop and plays a protective role against cardiac hypertrophy and remodeling. However, further investigation and clinical studies are needed to warrant the usefulness of FGF21 against cardiac hypertrophy.

\section{Molecular basis of anti-hypertrophic signaling cascades of FGF21}

The FGF21 activates cells to autocrine function by binding to FGFR1 on the cell membrane, using $\beta$-Klotho as a co receptor. This event activates the dimerization of the receptor and causes autophosphorylation of tyrosine kinase. Tyrosine kinase then recruits and phosphorylates FRS2 $\alpha$. The FRS2 $\alpha$ in turn affects four primary pathways, which in turn leads to the attenuation of cardiac hypertrophy. An illustrated diagram of the anti-hypertrophic effects of FGF21 in both the autocrine and endocrine manner by the loop autocrine function of FGF21 through the Sirt1/PPAR $\alpha$ pathway is shown in Fig. 3.

The first of these four pathways is the activation of the Erk1/2-CREB-Sirt1-PGC1 $\alpha$ signaling pathway as an autocrine function and autocrine loop regulation in FGF21-KO cardiomyocytes. This pathway leads to increased mitochondrial FAO enzyme genes expression including MCAD and mcpt $1 \alpha$, indicating increased cardiac mitochondrial FAO (Planavila et al. 2013). The second pathway involves the inhibition of the translocation of pro-inflammatory cytokines NFk $\beta$ into the nucleus to activate inflammatory cytokine expression including $\mathrm{TNF} \alpha$, IL6, and MCP1, resulting in a decrease in the

Published by Bioscientifica Ltd 


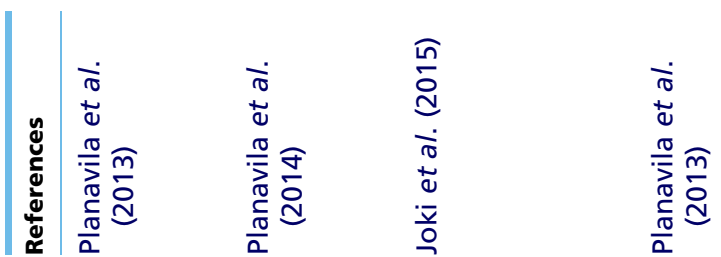
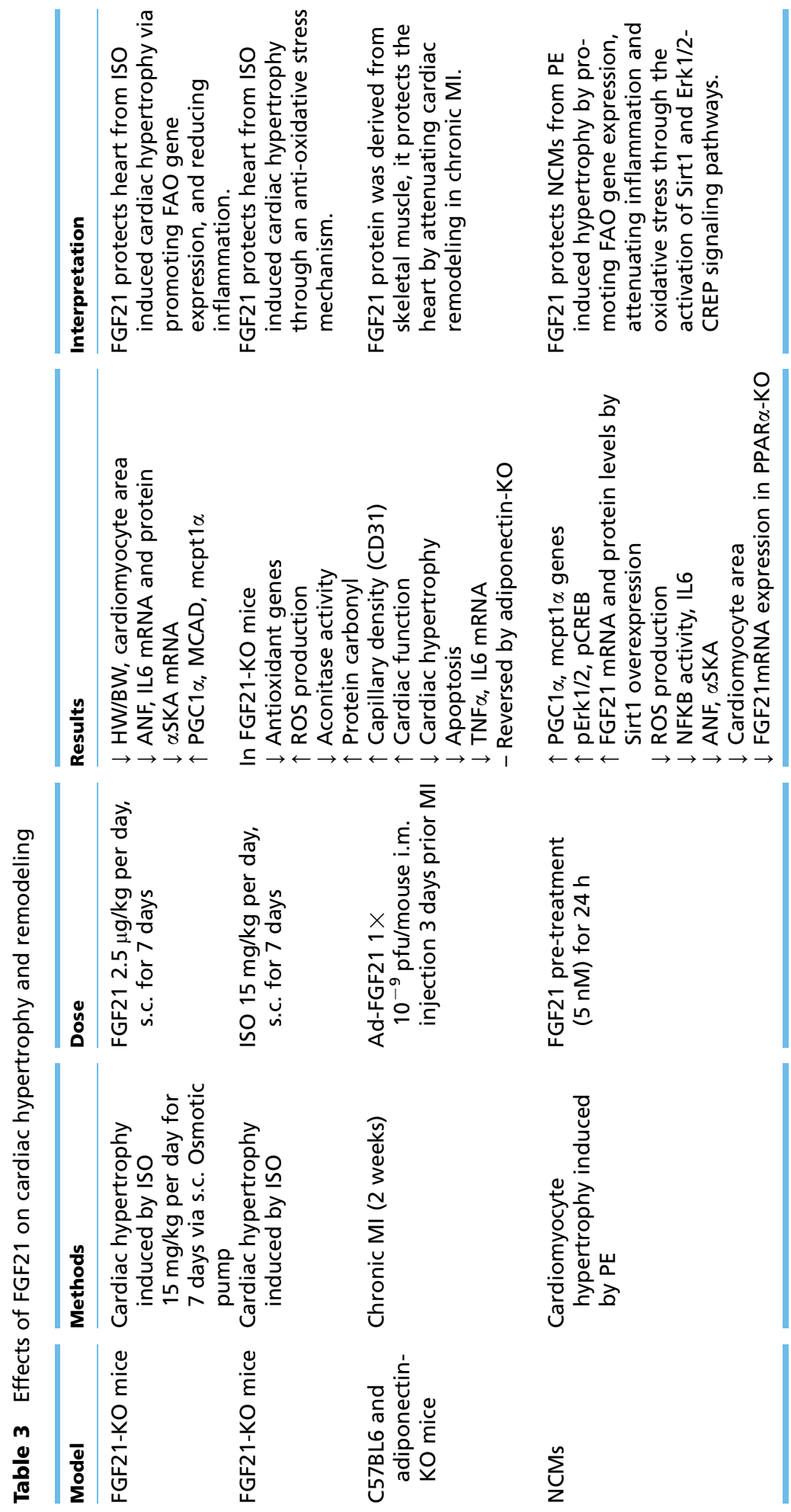


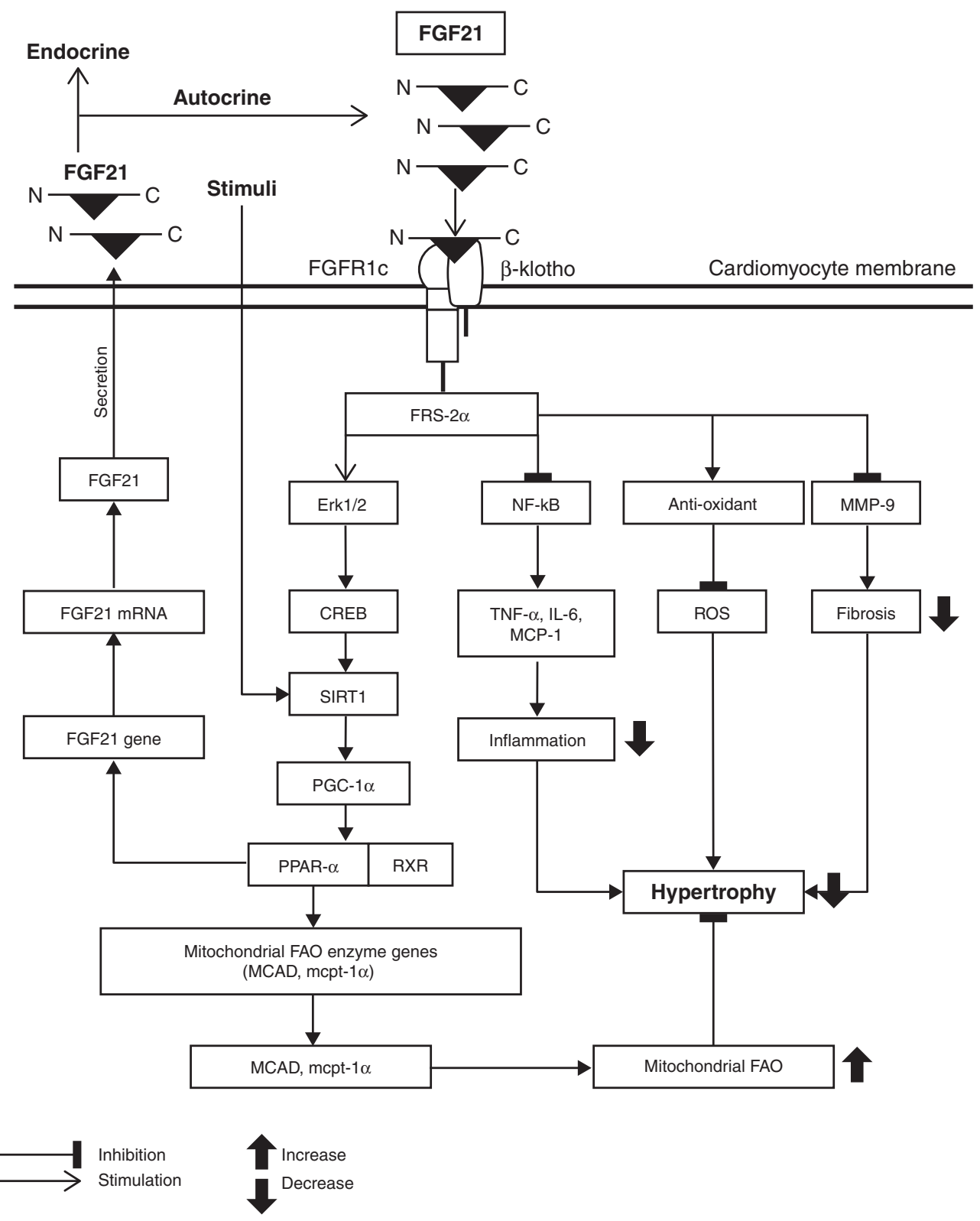

Figure 3

FGF21 signaling cascade in anti-hypertrophic effects of FGF21. FGF21 exerts anti-hypertrophic effects in autocrine and endocrine manners by loop autocrine function through the Sirt1/PPAR $\alpha$ pathway. FAO, fatty acid $\beta$ oxidation; PGC1 $\alpha$, peroxisome proliferator-activated receptor $1 \gamma$ coactivator $1 \alpha$; NFkB, nuclear factor Keppa B; SIRT1, sirtuin1; FGF21, fibroblast growth factors 21; FGFR1, fibroblast growth factors receptors 1; PPAR $\alpha$,

inflammatory processes (Planavila et al. 2013). The third pathway involves the inhibition of cardiac MMP9, which indicates a decrease in cardiac fibrotic formation following cardiac remodeling (Planavila et al. 2013). Finally, FGF21 activates the anti-oxidative pathway, resulting in the reduction of oxidative stress in the cells (Planavila et al. 2013, 2014). peroxisome proliferator activated receptor $\alpha$; MCAD, medium-chain acylCoA dehydrogenase; mcpt $1 \alpha$, carnitine palmitoyltransferase $1 \alpha$; Erk1/2, extracellular-signal-regulated kinases $1 / 2$; CREB, CAMP response elementbinding protein; RXR, retinoid X receptor; TNF $\alpha$, tumour necrosis factors $\alpha$; IL6, interleukin 6; MCP1, monocyte chemoattractant protein 1; MMP9, matrix metallopeptidase 9 .

\section{FGF21 protects the heart from diabetes induced cardiomyopathy}

Evidence regarding the protection of the heart from diabetes induced cardiomyopathy by FGF21 is summarized in Table 4. In FGF21 deficient mice, it has been shown that FGF21 is essential in the prevention of the

Published by Bioscientifica Ltd. 


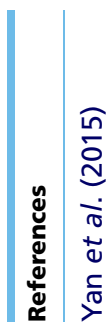

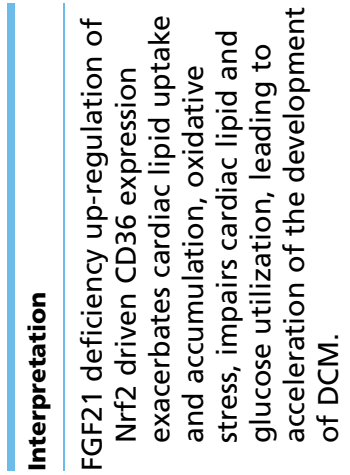

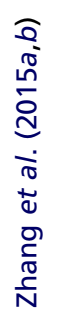

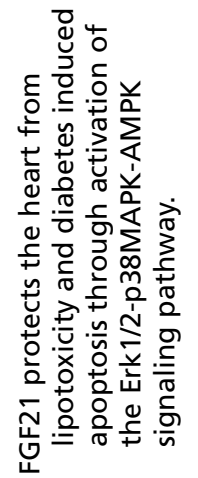

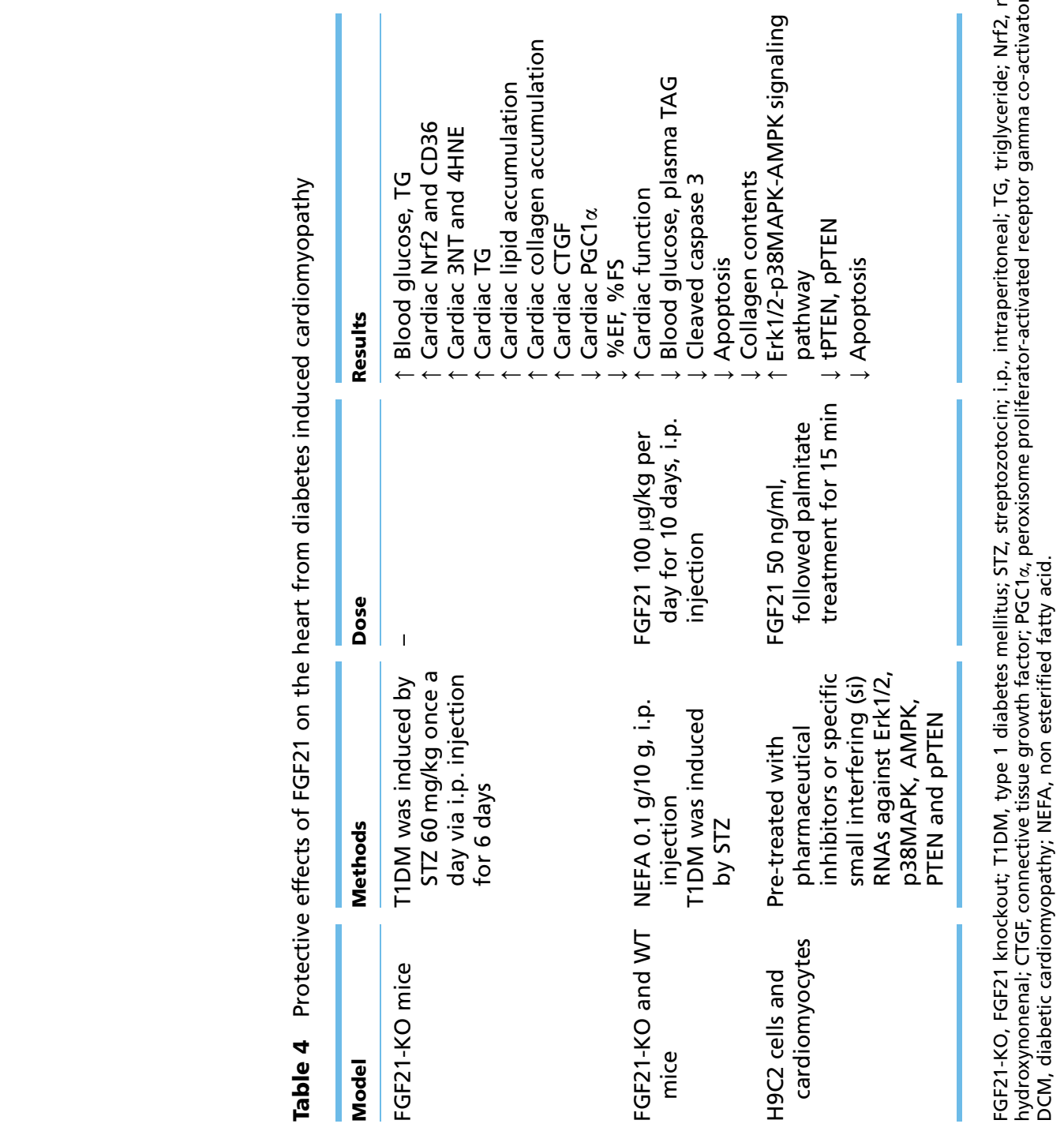

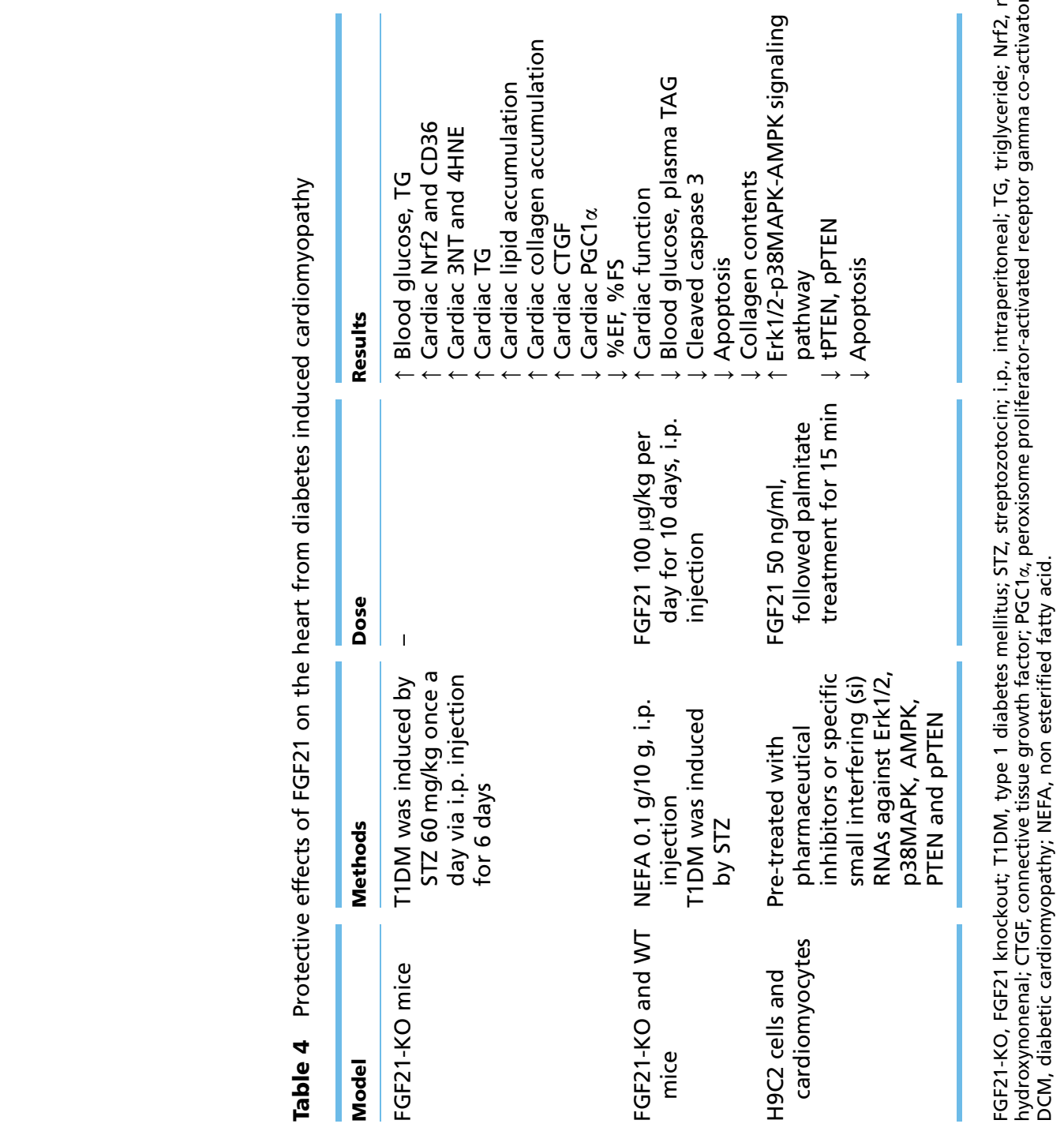

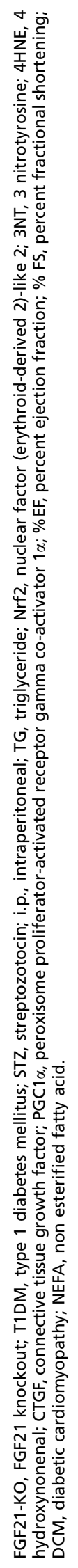


progression of T1DM induced cardiomyopathy (Yan et al. 2015). It has been proposed that four potential mechanisms are responsible for this adverse effect due to FGF21 deficiency. First, increased cardiac oxidative stress was observed, as shown by increased 3 nitrotyrosine (3NT) and 4 hydroxynonenal (4HNE). Second, increased nuclear factor (erythroid derived 2) like 2 (Nrf2) activated CD36 expression was seen, which led to increased plasma lipid uptake and accumulation into the cells. Third, decreased PGC1 $\alpha$ protein expression was observed, which led to decreased FAO thus promoting lipid uptake and accumulation in cardiomyocytes via the CD36 receptor on the cell membranes. Fourth, increased myocardial collagen accumulation was observed as shown by increased connective tissue growth factor (CTGF). In contrast, FGF21 administration can protect the heart from lipotoxicity and diabetes induced cardiac apoptosis by the activating of the Erk1/2-p38 MAPK-AMPK survival pathway leading to decreased cardiac apoptosis and improved cardiac function (Zhang et al. 2015a). An illustrated diagram of these mechanisms is shown in Fig. 4. It has been proposed that these four potential mechanisms cause left ventricular dysfunction and accelerate the development and progression of DCM (Yan et al. 2015) and the effects can be reversed by FGF21 treatment (Zhang et al. 2015a).

\section{FGF21 regulates energy supply in the heart}

FAO is the major source of energy for cardiomyocytes, generating $50-70 \%$ of ATP in a normal adult heart, while only $20-30 \%$ of energy is released by glycolysis, and $<5 \%$ from other sources (Neely et al. 1972, Neely \& Morgan 1974). It has been shown that the transition from fetal glycolysis (fetal pattern) to FAO in the neonatal stage (Lockwood \& Bailey 1970, Kelly et al. 1989 ) is brought about by increased PGC1 $\alpha$, PPAR $\alpha$, and FGF21 mRNA expression (Planavila et al. 2013). In contrast, the chicken ovalbumin upstream promoter transcription factor (COUP-TF) that regulates glycolysis is down regulated (Sack et al. 1997). PPAR $\alpha$ is expressed at a high rate in mitochondrial FAO tissue, and is situated on the nuclear membrane with the retinoid $\mathrm{X}$ receptor (RXR). PGC1 $\alpha$ binding to the PPAR $\alpha /$ RXR on the nuclear membrane leads to the increased expression of FAO genes including MCAD and mcpt $1 \alpha$, hence promoting increased $\mathrm{FAO}$ and synthesis of the ATP supply for the heart in physiological conditions (Vega et al. 2000) (Fig. 5A).
Under pathological conditions such as cardiac hypertrophy, myocardium FAO enzyme genes are down regulated (Sack et al. 1997, Razeghi et al. 2001), while the COUP-TF is up regulated (Sack et al. 1997). This caused the switch of the energy source back to the fetal glycolysis pattern again (Fig. 5B). A recent study demonstrated that myocardium PGC1 $\alpha, \mathrm{MCAD}$, and mcpt $1 \alpha$ mRNA expression is regulated by FGF21 to promote FAO for the energy supply to the heart (Planavila et al. 2013). The deletion of FGF21 has been shown to increase CD36 and decrease PGC1 $\alpha$, leading to acceleration of DCM through aggravating cardiac lipid accumulation (Yan et al. 2015). Therefore, FGF21 might be beneficial as a pharmacological intervention under these conditions. Further studies are needed to give more evidence for the substantiation to this hypothesis.

\section{Molecular basis of the antioxidant signaling cascade of FGF21 in cardiomyocytes}

Previous studies demonstrated that following ISO induced cardiac hypertrophy by causing cardiac oxidative stress and inflammation, and that FGF21 was secreted from cardiomyocytes via Sirt1 activation. Sirt1 was found to stimulate FGF21mRNA and protein expression and secretion into the circulation, where FGF21 proceeded to act in a paracrine, autocrine and endocrine manner. $\mathrm{n}$ the autocrine loop function, FGF21 induces anti-oxidant gene expression through the Erk/Sirt1 pathway, including uncoupling protein 3 (UCP3), superoxide dismutase 2 (Sod 2), peroxiredoxin $5(\operatorname{Prdx} 5)$, glutathione peroxidase 1 (GPX1), Catalase (CAT) and Sequestosome 1 (Sqstm1), resulting in a reduction in cardiac tissue injury (Planavila et al. 2014). Furthermore, FGF21 has been shown to activate the Nrf2 pathway in hepatocytes, which was found to lead to increased anti-oxidant gene expression, resulting in the reduction of liver tissue injury (Yu et al. 2015) (Fig. 6).

The stimulation of antioxidative pathways by FGF21 led to an increase in antioxidative gene and enzyme expression, and prevented oxidative stress by decreasing ROS production in cardiomocytes. Therefore, this protected the myocardium (Planavila et al. 2014) from oxidative stress and subsequent injury. Interestingly, a clinical study demonstrated that FGF21, UCP3, and Sod2 levels were increased in dilated cardiomyopathy patients in the final stages of heart failure (Planavila et al. 2014). This indicated that FGF21 could protect the cardiomyocytes or slow down the degree of damage following oxidative stress in a failing human heart.

Published by Bioscientifica Ltd. 


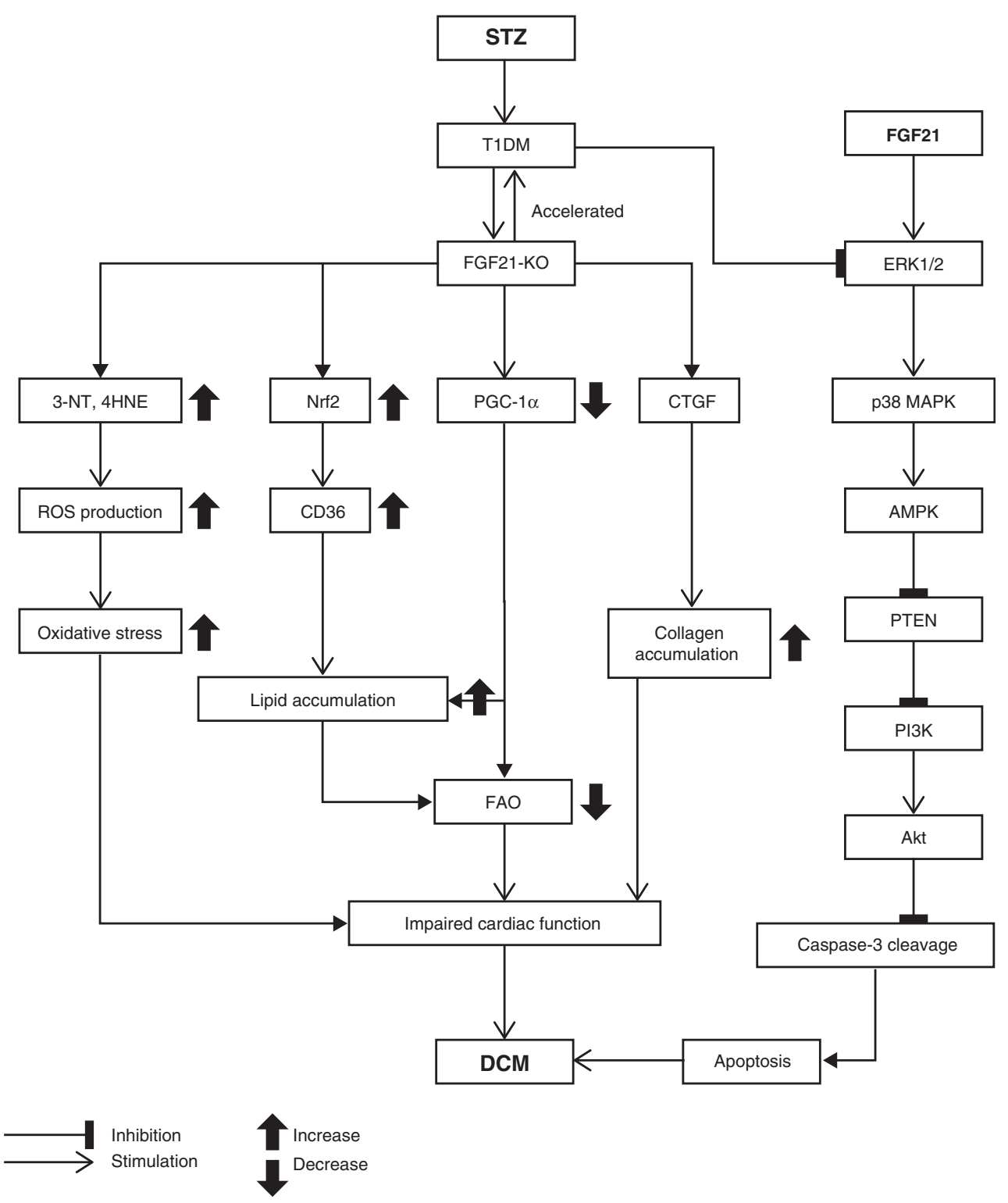

Figure 4

FGF21 protects the heart from diabetes induced cardiomyopathy. STZ, streptozotocin; T1DM, type 1 diabetes mellitus; FGF21-KO, FGF21 knockout; Nrf2, nuclear factor (erythroid-derived 2)-like 2; 3NT, 3 nitrotyrosine; $4 \mathrm{HNE}$, 4 hydroxynonenal; CTGF, connective tissue growth factor; $\mathrm{PGC1} \alpha$, peroxisome proliferator activated receptor gamma co-activator $1 \alpha$;

It has been shown that these signaling pathways of FGF21 have the crosstalk at the secondary messenger levels such as ERK1/2 for anti-apoptosis (Zhang et al. 2015a), anti-hypertrophic (Planavila et al. 2013, 2014), and anti-oxidative stress ( $\mathrm{Yu}$ et al. 2015) in the heart. Activation of FGFR/ $\beta$-Klotho complex therefore could activate these effects of FGF21 simultaneously at this crosstalk. However, further studies are needed to investigate this issue.
TG, triglyceride; FAO, fatty $\beta$ acid oxidation; DCM, diabetic cardiomyopathy; Erk, extracellular signal-regulated kinase; p38 MAPK, mitogen-activated protein kinase 14; PTEN, phosphatase and tensin homolougue; PI3K, phosphatidylinositol 3-kinase. Data from Yan et al. 2015, Zhang et al. 2015a.

\section{Clinical evidence of the association between FGF21 and cardiovascular alteration}

Evidence regarding the correlation of plasma FGF21 with cardiovascular alteration in clinical reports are summarized in Table 5. Serum FGF21 levels have been shown to have a strong correlation with waist circumference, systolic blood pressure, lower extremity arteriosclerotic disease (Zhang et al. 2015b) and carotid intima

Published by Bioscientifica Ltd. 
A
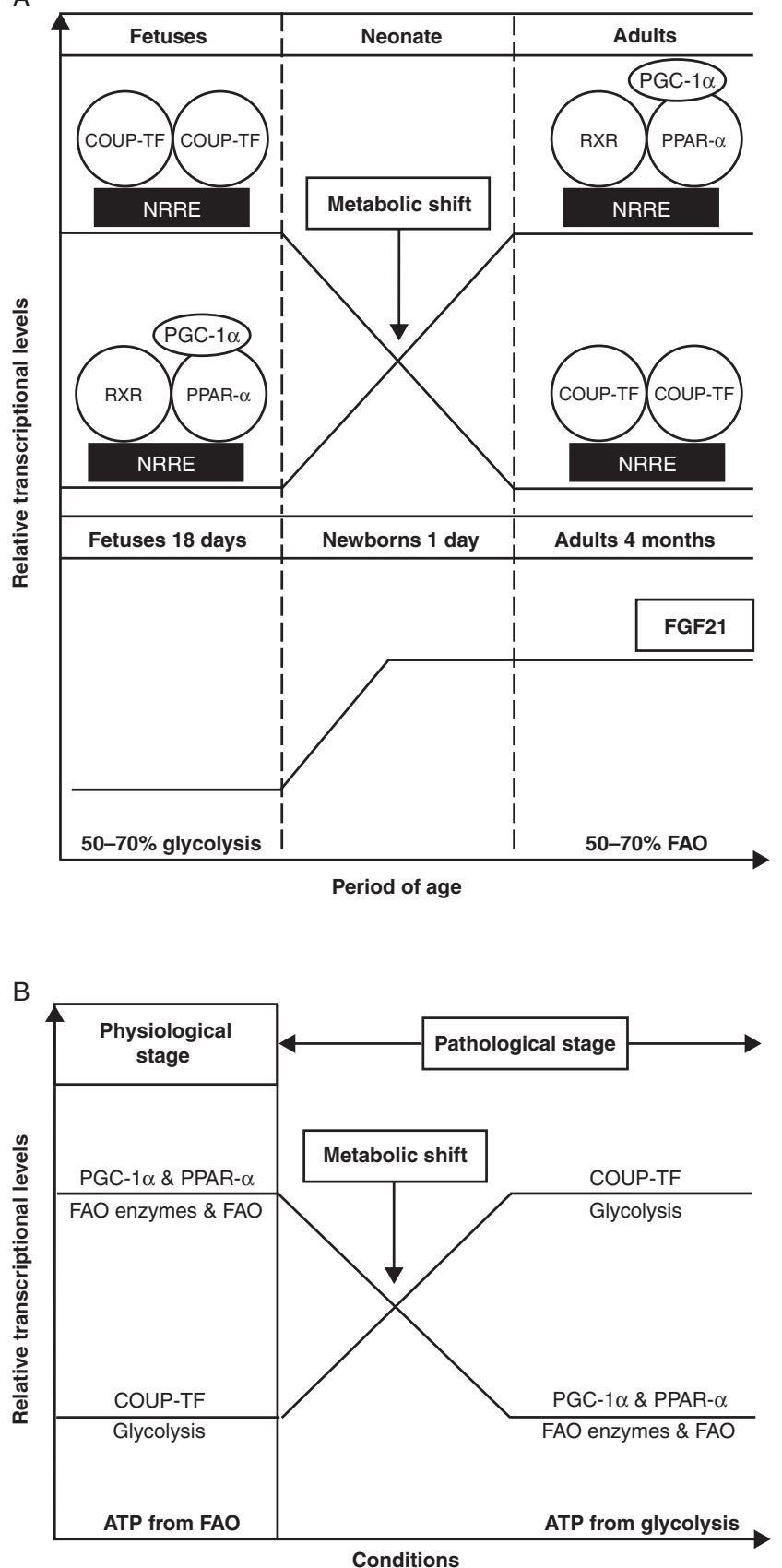

Figure 5

Relationship of FGF21 mRNA expression and FAO control in cardiomyocytes in different periods of age, and its alteration under physiological and pathological stages. (A) Relative transcriptional level of FGF21 mRNA and cardiac FAO enzyme gene regulator expression in different age brackets. (B) Relative transcriptional level of FGF21 mRNA and cardiac FAO enzyme gene regulator expression in physiological and pathological stages. $\mathrm{PGC1} \alpha$, peroxisome proliferator-activated receptor $1 \gamma$ coactivator $1 \alpha$; RXR, retinoid $X$ receptor; $\operatorname{PPAR} \alpha$, peroxisome proliferator activated receptor- $\alpha$; COUP-TF, chicken ovalbumin upstream promoter transcription factor; NRRE, nuclear receptor response element; FAO, fatty acid $\beta$ oxidation; ATP, Adenosine triphosphate.

http://joe.endocrinology-journals.org DOI: $10.1530 / J O E-15-0289$
() 2015 Society for Endocrinology Printed in Great Britain media thickness (Chow et al. 2013) in T2DM (type 2 diabetes mellitus) patients. FGF21 level was also increased in atrial fibrillation $(\mathrm{AF})$ patients and was shown to be an independent risk factor for AF (Han et al. 2015). In the cases of non-alcoholic fatty liver disease (NAFLD) and CAD, the serum FGF21 was associated with an adverse lipid profile and also showed a positive correlation with total cholesterol (TC) and triglycerides (TG) (Shen et al. 2013). Moreover, the CAD patient's serum FGF21 levels were also positively correlated with TG, fasting blood glucose, ApoB100, insulin, and HOMA-IR, and also have a negative correlation with HDL, and ApoA1 (Lin et al. 2010). Recent studies demonstrated that serum FGF21 levels correlate with metabolic status in patients. High serum FGF21 levels in several pathological conditions of the heart under metabolic dysregulation may be explained by FGF21 resistance conditions, which have been observed in ex vivo experiments with obese rat hearts (Patel et al. 2014) and in vivo experiments with DIO mice liver and white adipose tissue (Fisher et al. 2010). Therefore, serum FGF21 levels may be indicators of adverse metabolic dysregulation and prognosis for CVD.

The term 'FGF21 resistance' in the heart was first mentioned in chronic DIO rats by Patel and colleagues (Patel et al. 2014). They found that obese rat hearts had increased FGF21 mRNA, and FGF21 protein expression and secretion levels. Despite the high level of FGF21, disrupted FGF21-FGFR1- $\beta$-Klotho signaling and decreased ERK1/2, Akt and AMPK phosphorylation were observed under this condition (Patel et al. 2014). These findings indicate that obese condition caused the impairment of the FGF21 signaling cascades, and that the feedback mechanism allowed the increased production of FGF21 to overcome the FGF21 receptor signaling dysfunction. Unfortunately, the increased endogenous FGF21 level was not sufficient when the exogenous FGF21 administration comes into play a role for therapeutic strategy. The FGF21 resistance was also observed in clinical reports where serum FGF21 level was significantly increased in nonNAFLD (Shen et al. 2013), coronary heart disease (Lin et al. 2010, Shen et al. 2013), metabolic syndrome (Lee et al. 2014), and T2DM (Lenart-Lipinska et al. 2013). This condition is similar to what has been observed in subjects under 'insulin resistance' condition in which the impairment of insulin receptor and signaling cascades was found with increased plasma insulin level (Pratchayasakul et al. 2011, Pipatpiboon et al. 2012).

The cross sectional study in 15 male patients who underwent aorto-coronary bypass surgery showed that

Published by Bioscientifica Ltd 


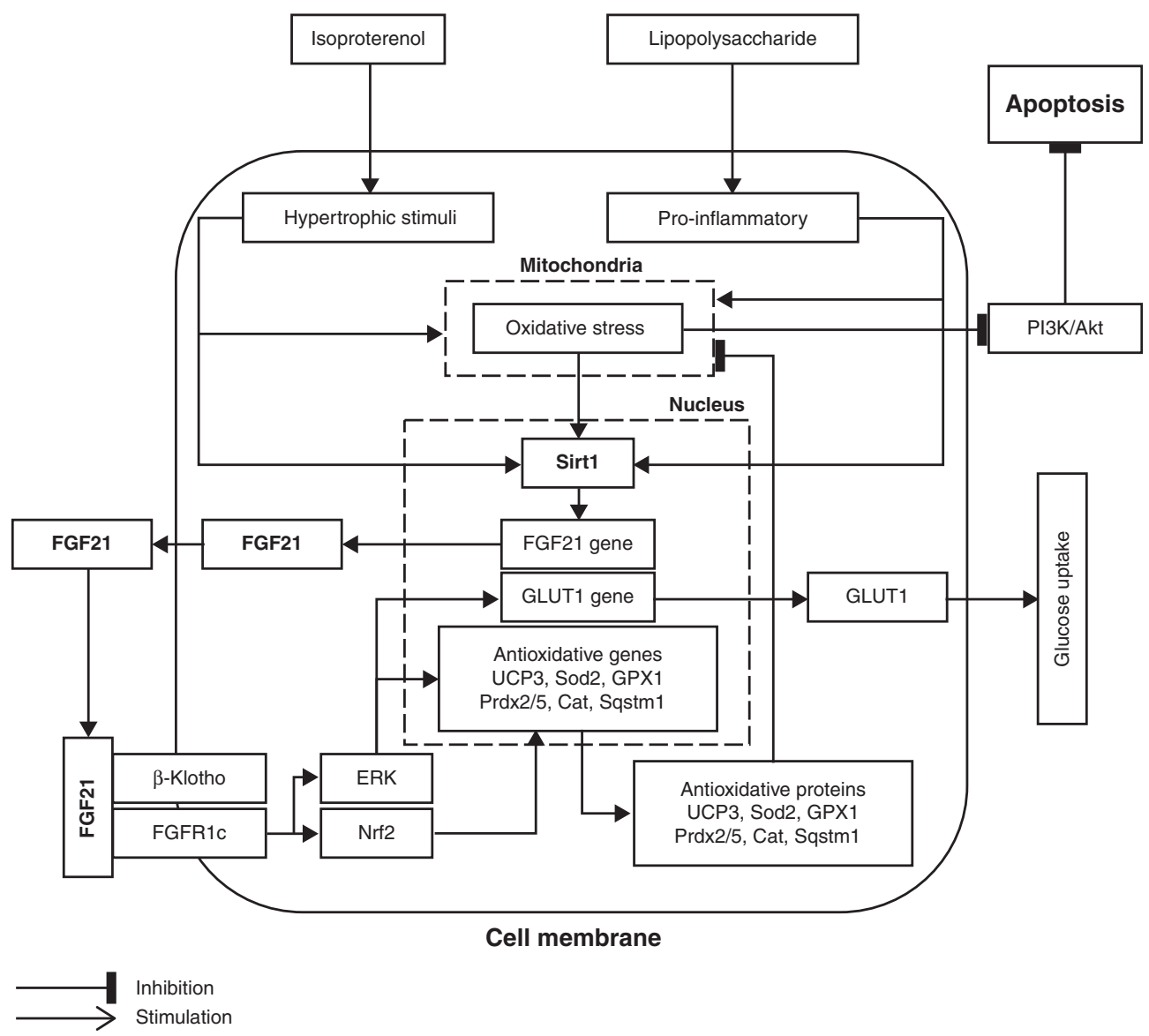

Figure 6

FGF21 mediates and plays a role in protecting against oxidative stress in cardiomyocytes. Sirt1, sirtuin 1; UCP3, uncoupling protein-3; Sod2, superoxide dismutase-2; Prdx2/5, peroxiredoxin-2/5; Cat, catalase; GPX1, glutathione

serum FGF21 levels increased to a peak at $6 \mathrm{~h}$ into surgery, and were associated with increased serum glucose, insulin, pro-inflammatory cytokines (TNF $\alpha, \mathrm{MCP} 1)$ and inflammatory cytokines (IL6, 8), but returned to baseline at $96 \mathrm{~h}$ after surgery (Kotulak et al. 2011). Moreover, epicardial fat and muscular FGF21 mRNA expression increased after surgery has reacted positively with blood glucose levels at the end of surgery (Kotulak et al. 2011) indicating that FGF21 mRNA expression and serum FGF21 levels regulated glucose homeostasis, increased the insulin sensitivity and attenuated the inflammatory process.

In a cross sectional study of 189 patients who underwent cardiac multidetector coronary computed tomography, it was found that serum FGF21 levels were associated with an adverse lipid profile and pericardial fat volume only in metabolic syndrome patients (Lee et al. 2014). Interestingly, cardiac tissue peroxidase 1; Sqstm1, sequestosome 1; ROS, reactive oxygen species; Nrf2, Nuclear factor erythroid 2-related factor 2; PI3K, phosphatidylinositol 3-kinase. Data from Planavila et al. (2014) and Yu et al. (2015).

FGF21 mRNA and antioxidant genes (UCP3 and Sod2) are upregulated in six failing human hearts which may be mechanisms to preserve myocardial function in cases of heart failure (Planavila et al. 2014). All of these findings indicate that FGF21 plays an important role in metabolic regulation and attenuates cardiac oxidative stress in heart failure patients. The increased FGF21 level observed in heart failure patients was due to the FGF21 resistance as shown by a previous report (Planavila et al. 2014). Despite the increased endogenous FGF21 under this pathological condition, its level was still not sufficient to overcome the FGF21 resistance. Therefore, the role of exogenous FGF21 is considered as a potential therapeutic strategy to provide cardioprotective effects (Lu et al. 2010, Cong et al. 2013, Planavila et al. 2013, 2014, Zhang et al. 2015a). Previous reports at least from basic studies using exogenous FGF21 demonstrating the

Published by Bioscientifica Ltd. 


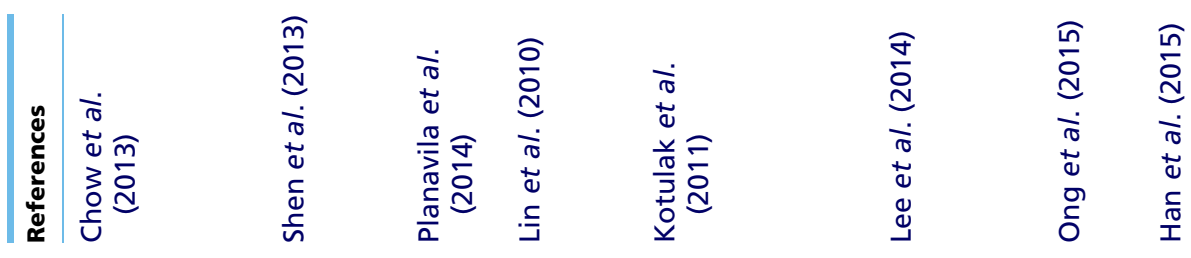

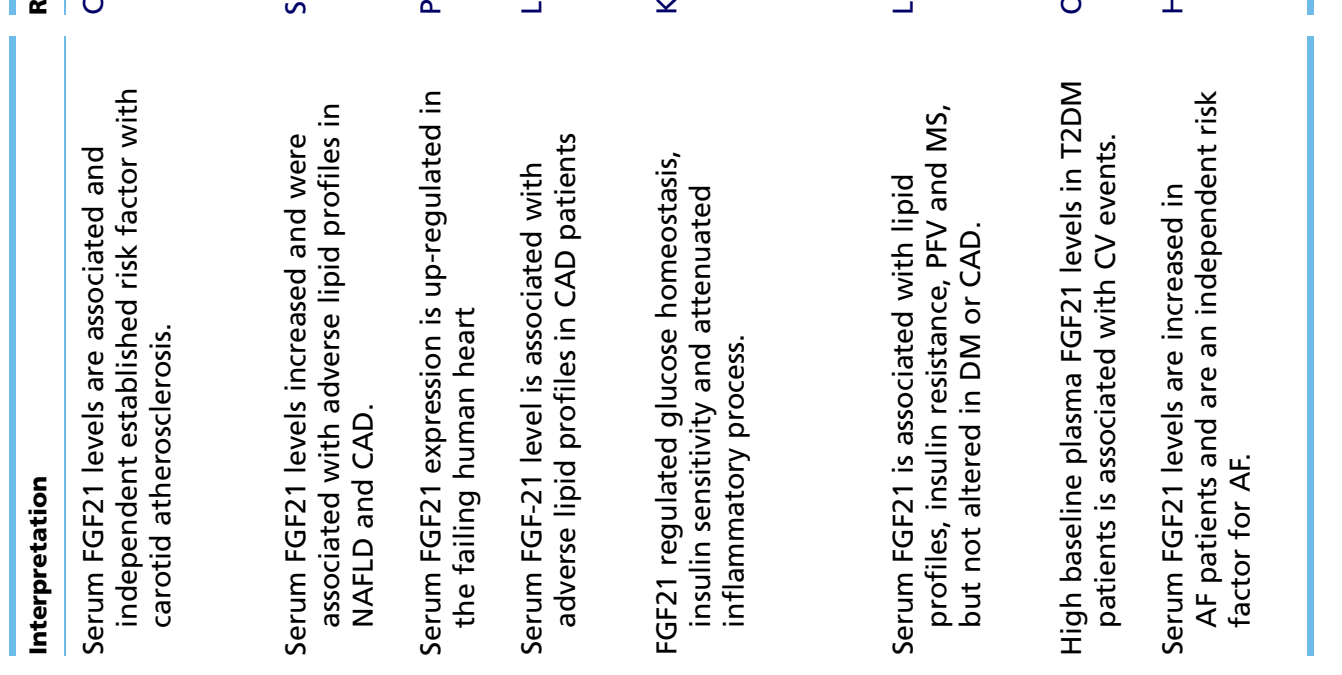

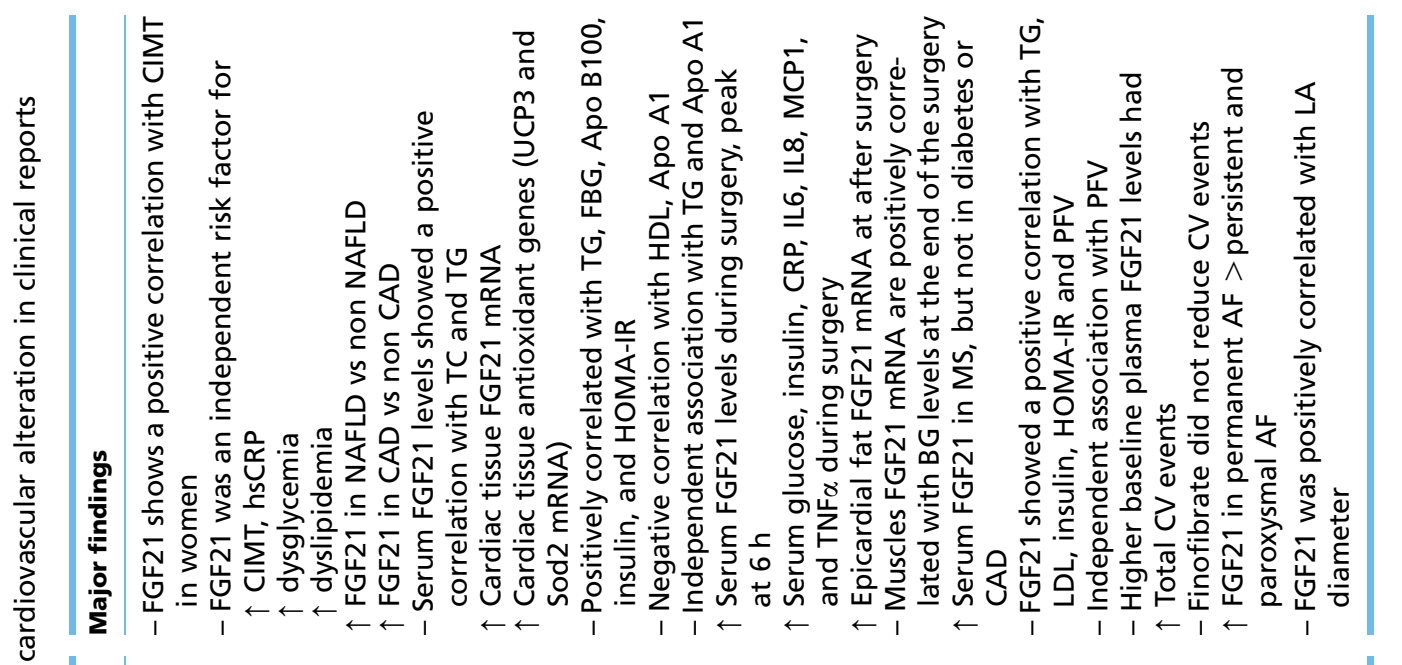

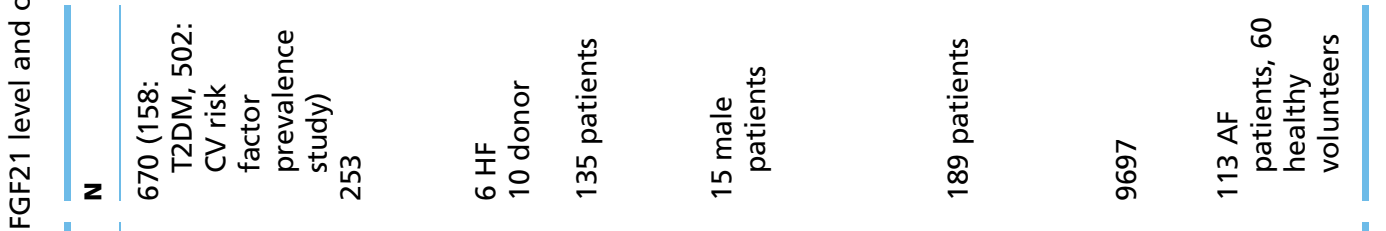

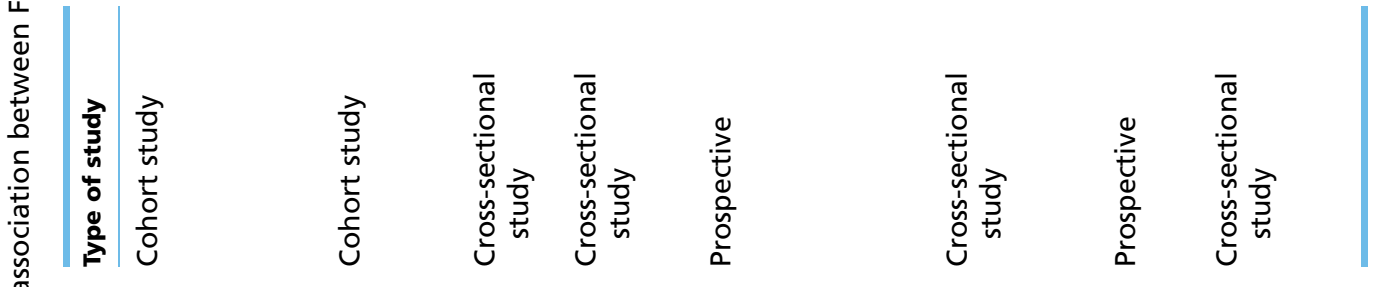

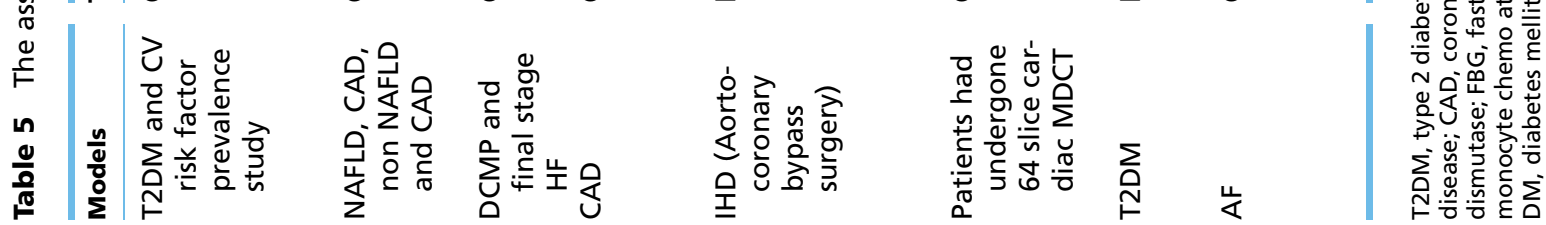


improved cardiac function in cardiac I/R injury (Cong et al. 2013, Liu et al. 2013, Patel et al. 2014), cardiac hypertrophy (Planavila et al. 2013), and DCM (Zhang et al. 2015a) supported this hypothesis.

Although previous studies indicated that PPAR $\alpha$ is the essential downstream signaling protein in regulating the expression of FGF21 mRNA in cardiomyocytes, and preserving the myocardial metabolism through regulating the FAO (Lu et al. 2010, Planavila et al), PPAR a agonist (Finofibrate) has been shown to be unable to reduce cardiovascular events in T2DM patients after a 5-year follow-up (Ong et al. 2015). Moreover, the risk cardiovascular events in T2DM patients showed a correlation with baseline plasma FGF21 levels. Higher baseline plasma FGF21 levels correlated with an increased risk of cardiovascular events (Ong et al. 2015). This suggests that plasma FGF21 levels could be used as a biomarker of metabolic dysregulation, and increased plasma FGF21 levels may be indicative of a higher risk of cardiovascular events.

Despite the fact that FGF21 can preserve the heart in several pathological conditions, FGF21 resistance may be a limitation for the potential role of exogenous FGF21 administration. However, previous studies demonstrated that exogenous FGF21 exerted its effects in a dosedependent manner (Cong et al. 2013, Planavila et al. 2014, Yu et al. 2015). Moreover, it is possible that FGF21 replacement during an early stage of FGF21 resistance may be more effective than late replacement. Future studies are needed to prove this hypothesis. Furthermore, long-term FGF21 treatment (Zhang et al. 2015a) may provide better outcome than the acute intervention (Patel et al. 2014). Lastly, combined therapy of FGF21 with specific drugs may provide better efficacy than FGF21 monotherapy. All of these hypothetical strategies still need to be verified in future studies.

\section{Conclusion}

Experimental studies of FGF21 in the heart have consistently demonstrated its beneficial effects in in vitro, ex vivo and in vivo models. Evidence has shown that FGF21 is crucial for cardioprotection in myocardial hypertrophy, ischemia, DCM and I/R injury. FGF21 provides its therapeutic benefits by attenuating apoptosis, oxidative stress and inflammation, and improving energy supply, and therefore could be used as an indicator of metabolic dysregulation. Moreover, FGF21 could be a potential therapeutic target for metabolic disorders and CVD in the future.

\section{Declaration of interest}

The authors declare that there is no conflict of interest that could be perceived as prejudicing the impartiality of this review.

\section{Funding}

This work was supported by a NSTDA Research Chair Grant from the National Science and Technology Development Agency Thailand (NC), the Thailand Research Fund Royal Golden Jubilee Program (SC and PT), BRG5780016 (SC), and Chiang Mai University Center of Excellence Award (NC).

\section{References}

Badman MK, Koester A, Flier JS, Kharitonenkov A \& Maratos-Flier E 2009 Fibroblast growth factor 21-deficient mice demonstrate impaired adaptation to ketosis. Endocrinology 150 4931-4940. (doi:10.1210/en. 2009-0532)

Beenken A \& Mohammadi M 2009 The FGF family: biology, pathophysiology and therapy. Nature Reviews. Drug Discovery 8 235-253. (doi:10.1038/nrd2792)

Chow WS, Xu A, Woo YC, Tso AW, Cheung SC, Fong CH, Tse HF, Chau MT, Cheung BM \& Lam KS 2013 Serum fibroblast growth factor-21 levels are associated with carotid atherosclerosis independent of established cardiovascular risk factors. Arteriosclerosis, Thrombosis, and Vascular Biology 33 2454-2459. (doi:10.1161/ATVBAHA.113.301599)

Cong WT, Ling J, Tian HS, Ling R, Wang Y, Huang BB, Zhao T, Duan YM, Jin LT \& Li XK 2013 Proteomic study on the protective mechanism of fibroblast growth factor 21 to ischemia-reperfusion injury. Canadian Journal of Physiology and Pharmacology 91 973-984. (doi:10.1139/cjpp2012-0441)

Ding X, Boney-Montoya J, Owen BM, Bookout AL, Coate KC, Mangelsdorf DJ \& Kliewer SA $2012 \beta$ Klotho is required for fibroblast growth factor 21 effects on growth and metabolism. Cell Metabolism 16 387-393. (doi:10.1016/j.cmet.2012.08.002)

Fisher FM, Chui PC, Antonellis PJ, Bina HA, Kharitonenkov A, Flier JS \& Maratos-Flier E 2010 Obesity is a fibroblast growth factor 21 (FGF21)resistant state. Diabetes 59 2781-2789. (doi:10.2337/db10-0193)

Gheorghiade M \& Bonow RO 1998 Chronic heart failure in the United States: a manifestation of coronary artery disease. Circulation $\mathbf{9 7}$ 282-289. (doi:10.1161/01.CIR.97.3.282)

Goetz R \& Mohammadi M 2013 Exploring mechanisms of FGF signalling through the lens of structural biology. Nature Reviews. Molecular Cell Biology 14 166-180. (doi:10.1038/nrm3528)

Hale C, Chen MM, Stanislaus S, Chinookoswong N, Hager T, Wang M, Veniant MM \& Xu J 2012 Lack of overt FGF21 resistance in two mouse models of obesity and insulin resistance. Endocrinology 153 69-80. (doi:10.1210/en.2010-1262)

Han X, Chen C, Cheng G, Xie C, Yang M, Shou X \& Sun C 2015 Serum fibroblast growth factor 21 levels are increased in atrial fibrillation patients. Cytokine 73 176-180. (doi:10.1016/j.cyto.2015.02.019)

Heather LC, Catchpole AF, Stuckey DJ, Cole MA, Carr CA \& Clarke K 2009 Isoproterenol induces in vivo functional and metabolic abnormalities: similar to those found in the infarcted rat heart. Journal of Physiology and Pharmacology 60 31-39.

Hotta Y, Nakamura H, Konishi M, Murata Y, Takagi H, Matsumura S, Inoue K, Fushiki T \& Itoh N 2009 Fibroblast growth factor 21 regulates lipolysis in white adipose tissue but is not required for ketogenesis and triglyceride clearance in liver. Endocrinology 150 4625-4633. (doi:10.1210/en.2009-0119)

Ito S, Kinoshita S, Shiraishi N, Nakagawa S, Sekine S, Fujimori T \& Nabeshima YI 2000 Molecular cloning and expression analyses of mouse $\beta$ klotho, which encodes a novel Klotho family protein.

Published by Bioscientifica Ltd 
Mechanisms of Development 98 115-119. (doi:10.1016/S09254773(00)00439-1)

Itoh N \& Ornitz DM 2011 Fibroblast growth factors: from molecular evolution to roles in development, metabolism and disease. Journal of Biochemistry 149 121-130. (doi:10.1093/jb/mvq121)

Itoh N \& Ohta H 2013 Pathophysiological roles of FGF signaling in the heart. Frontiers in Physiology 4 247. (doi:10.3389/fphys.2013.00247)

Joki Y, Ohashi K, Yuasa D, Shibata R, Ito M, Matsuo K, Kambara T, Uemura Y, Hayakawa S \& Hiramatsu-Ito M 2015 FGF21 attenuates pathological myocardial remodeling following myocardial infarction through the adiponectin-dependent mechanism. Biochemical and Biophysical Research Communications 459 124-130. (doi:10.1016/j.bbrc.2015. 02.081)

Kelly DP, Gordon JI, Alpers R \& Strauss AW 1989 The tissue-specific expression and developmental regulation of two nuclear genes encoding rat mitochondrial proteins. Medium chain acyl-CoA dehydrogenase and mitochondrial malate dehydrogenase. Journal of Biological Chemistry 264 18921-18925.

Kharitonenkov A 2008 FGF-21/FGF-21 receptor interaction and activation is determined by $\beta$ Klotho. Journal of Cellular Physiology 215 1-7. (doi:10.1002/jcp.21357)

Kharitonenkov A 2009 FGFs and metabolism. Current Opinion in Pharmacology 9 805-810. (doi:10.1016/j.coph.2009.07.001)

Kotulak T, Drapalova J, Kopecky P, Lacinova Z, Kramar P, Riha H, Netuka I, Maly J, Housa D, laha J et al. 2011 Increased circulating and epicardial adipose tissue mRNA expression of fibroblast growth factor-21 after cardiac surgery: possible role in postoperative inflammatory response and insulin resistance. Physiological Research 60 757-767.

Lee Y, Lim S, Hong ES, Kim JH, Moon MK, Chun EJ, Choi SI, Kim YB, Park YJ, Park KS et al. 2014 Serum FGF21 concentration is associated with hypertriglyceridaemia, hyperinsulinaemia and pericardial fat accumulation, independently of obesity, but not with current coronary artery status. Clinical Endocrinology 80 57-64. (doi:10.1111/cen.12134)

Lenart-Lipinska M, Matyjaszek-Matuszek B, Gernand W, Nowakowski A \& Solski J 2013 Serum fibroblast growth factor 21 is predictive of combined cardiovascular morbidity and mortality in patients with type 2 diabetes at a relatively short-term follow-up. Diabetes Research and Clinical Practice 101 194-200. (doi:10.1016/j.diabres.2013.04.010)

Lin Z, Wu Z, Yin X, Liu Y, Yan X, Lin S, Xiao J, Wang X, Feng W \& Li X 2010 Serum levels of FGF-21 are increased in coronary heart disease patients and are independently associated with adverse lipid profile. PLOS ONE $\mathbf{5}$ e15534. (doi:10.1371/journal.pone.0015534)

Liu SQ, Tefft BJ, Roberts DT, Zhang LQ, Ren Y, Li YC, Huang Y, Zhang D, Phillips HR \& Wu YH 2012 Cardioprotective proteins upregulated in the liver in response to experimental myocardial ischemia. American Journal of Physiology. Heart and Circulatory Physiology 303 H1446-H1458. (doi:10.1152/ajpheart.00362.2012)

Liu SQ, Roberts D, Kharitonenkov A, Zhang B, Hanson SM, Li YC, Zhang LQ \& Wu YH 2013 Endocrine protection of ischemic myocardium by FGF21 from the liver and adipose tissue. Scientific Reports 32767. (doi:10.1038/srep02767)

Lockwood EA \& Bailey E 1970 Fatty acid utilization during development of the rat. Biochemical Journal 120 49-54. (doi:10.1042/bj1200049)

Lu Y, Liu JH, Zhang LK, Du J, Zeng XJ, Hao G, Huang J, Zhao DH, Wang GZ $\&$ Zhang YC 2010 Fibroblast growth factor 21 as a possible endogenous factor inhibits apoptosis in cardiac endothelial cells. Chinese Medical Journal 123 3417-3421. (doi:10.3760/cma.j.issn.0366-6999.2010. 23.008)

Mohammadi M, Olsen SK \& Ibrahimi OA 2005 Structural basis for fibroblast growth factor receptor activation. Cytokine \& Growth Factor Reviews 16 107-137. (doi:10.1016/j.cytogfr.2005.01.008)

Neely JR \& Morgan HE 1974 Relationship between carbohydrate and lipid metabolism and the energy balance of heart muscle. Annual Review of Physiology 36 413-459. (doi:10.1146/annurev.ph.36.030174.002213)
Neely JR, Rovetto MJ \& Oram JF 1972 Myocardial utilization of carbohydrate and lipids. Progress in Cardiovascular Diseases 15 289-329. (doi:10.1016/0033-0620(72)90029-1)

Nishimura T, Nakatake Y, Konishi M \& Itoh N 2000 Identification of a novel FGF, FGF-21, preferentially expressed in the liver. Biochimica et Biophysica Acta 1492 203-206. (doi:10.1016/S0167-4781(00)00067-1)

Ong KL, Januszewski AS, O'Connell R, Jenkins AJ, Xu A, Sullivan DR, Barter PJ, Hung WT, Scott RS, Taskinen MR et al. 2015 The relationship of fibroblast growth factor 21 with cardiovascular outcome events in the Fenofibrate Intervention and Event Lowering in Diabetes study. Diabetologia 58 464-473. (doi:10.1007/s00125-014-3458-7)

Patel V, Adya R, Chen J, Ramanjaneya M, Bari MF, Bhudia SK, Hillhouse EW, Tan BK \& Randeva HS 2014 Novel insights into the cardio-protective effects of FGF21 in lean and obese rat hearts. PLOS ONE 9 e87102. (doi:10.1371/journal.pone.0087102)

Pipatpiboon N, Pratchayasakul W, Chattipakorn N \& Chattipakorn SC 2012 PPARgamma agonist improves neuronal insulin receptor function in hippocampus and brain mitochondria function in rats with insulin resistance induced by long term high-fat diets. Endocrinology 153 329-338. (doi:10.1210/en.2011-1502)

Planavila A, Redondo I, Hondares E, Vinciguerra M, Munts C, Iglesias R, Gabrielli LA, Sitges M, Giralt M, van Bilsen M et al. 2013 Fibroblast growth factor 21 protects against cardiac hypertrophy in mice. Nature Communications 4 2019. (doi:10.1038/ncomms3019)

Planavila A, Redondo-Angulo I, Ribas F, Garrabou G, Casademont J, Giralt M \& Villarroya F 2014 Fibroblast growth factor 21 protects the heart from oxidative stress. Cardiovascular Research 106 19-31. (doi:10.1093/cvr/cvu263)

Potthoff MJ, Inagaki T, Satapati S, Ding X, He T, Goetz R, Mohammadi M, Finck BN, Mangelsdorf DJ, Kliewer SA et al. 2009 FGF21 induces PGC- $1 \alpha$ and regulates carbohydrate and fatty acid metabolism during the adaptive starvation response. PNAS 106 10853-10858. (doi:10.1073/ pnas.0904187106)

Pratchayasakul W, Kerdphoo S, Petsophonsakul P, Pongchaidecha A, Chattipakorn N \& Chattipakorn SC 2011 Effects of high-fat diet on insulin receptor function in rat hippocampus and the level of neuronal corticosterone. Life Science 88 619-627. (doi:10.1016/j.lfs.2011.02.003)

Razeghi P, Young ME, Alcorn JL, Moravec CS, Frazier OH \& Taegtmeyer H 2001 Metabolic gene expression in fetal and failing human heart. Circulation 104 2923-2931. (doi:10.1161/hc4901.100526)

Sack MN, Disch DL, Rockman HA \& Kelly DP 1997 A role for Sp and nuclear receptor transcription factors in a cardiac hypertrophic growth program. PNAS 94 6438-6443. (doi:10.1073/pnas.94.12.6438)

Shen Y, Ma X, Zhou J, Pan X, Hao Y, Zhou M, Lu Z, Gao M, Bao Y \& Jia W 2013 Additive relationship between serum fibroblast growth factor 21 level and coronary artery disease. Cardiovascular Diabetology 12124. (doi:10.1186/1475-2840-12-124)

Suzuki M, Uehara Y, Motomura-Matsuzaka K, Oki J, Koyama Y, Kimura M, Asada M, Komi-Kuramochi A, Oka S \& Imamura T 2008 Klotho is required for fibroblast growth factor (FGF) 21 signaling through FGF receptor (FGFR) 1c and FGFR3c. Molecular Endocrinology 22 1006-1014. (doi:10.1210/me.2007-0313)

Vega RB, Huss JM \& Kelly DP 2000 The coactivator PGC-1 cooperates with peroxisome proliferator-activated receptor $\alpha$ in transcriptional control of nuclear genes encoding mitochondrial fatty acid oxidation enzymes. Molecular and Cellular Biology 20 1868-1876. (doi:10.1128/MCB.20.5. 1868-1876.2000)

Wente W, Efanov AM, Brenner M, Kharitonenkov A, Koster A, Sandusky GE, Sewing S, Treinies I, Zitzer H \& Gromada J 2006 Fibroblast growth factor-21 improves pancreatic $\beta$-cell function and survival by activation of extracellular signal-regulated kinase $1 / 2$ and Akt signaling pathways. Diabetes 55 2470-2478. (doi:10.2337/db05-1435)

Wu X, Qi YF, Chang JR, Lu WW, Zhang JS, Wang SP, Cheng SJ, Zhang M, Fan Q \& Lv Y 2014 Possible role of fibroblast growth factor 21 on atherosclerosis via amelioration of endoplasmic reticulum 
stress-mediated apoptosis in apoE mice. Heart and Vessels 30 657-668. (doi:10.1007/s00380-014-0557-9)

Yan X, Chen J, Zhang C, Zhou S, Zhang Z, Chen J, Feng W, Li X \& Tan Y 2015 FGF21 deletion exacerbates diabetic cardiomyopathy by aggravating cardiac lipid accumulation. Journal of Cellular and Molecular Medicine 19 1157-1568. (doi:10.1111/jcmm.12530)

Yie J, Hecht R, Patel J, Stevens J, Wang W, Hawkins N, Steavenson S, Smith S, Winters D, Fisher S et al. 2009 FGF21 N- and C-termini play different roles in receptor interaction and activation. FEBS Letters 583 19-24. (doi:10.1016/j.febslet.2008.11.023)

Yu Y, Bai F, Liu Y, Yang Y, Yuan Q, Zou D, Qu S, Tian G, Song L \& Zhang T 2015 Fibroblast growth factor (FGF21) protects mouse liver against
D-galactose-induced oxidative stress and apoptosis via activating Nrf2 and PI3K/Akt pathways. Molecular and Cellular Biochemistry 403 287-299. (doi:10.1007/s11010-015-2358-6)

Zhang C, Huang Z, Gu J, Yan X, Lu X, Zhou S, Wang S, Shao M, Zhang F \& Cheng P 2015a Fibroblast growth factor 21 protects the heart from apoptosis in a diabetic mouse model via extracellular signal-regulated kinase 1/2-dependent signalling pathway. Diabetologia 58 1937-1948. (doi:10.1007/s00125-015-3630-8)

Zhang X, Hu Y, Zeng H, Li L, Zhao J, Zhao J, Liu F, Bao Y \& Jia W $2015 b$ Serum fibroblast growth factor 21 levels is associated with lower extremity atherosclerotic disease in Chinese female diabetic patients. Cardiovascular Diabetology 14 190. (doi:10.1186/s12933-015-0190-7)

Received in final form 19 August 2015

Accepted 4 September 2015

Accepted Preprint published online 4 September 2015
Published by Bioscientifica Ltd. 